\title{
An Experimental and Computational Study of
}

\section{$\beta-\mathrm{AgVO}_{3}$ : Optical Properties and Formation of}

\section{Ag Nanoparticles}

Regiane Cristina de Oliveira ${ }^{1}$, Marcelo Assis ${ }^{l}$, Mayara Mondego Teixeira ${ }^{1}$, Maya

Dayana Penha da Silva ${ }^{1}$, Máximo Siu Li ${ }^{2}$, Juan Andres ${ }^{3 *}$, Lourdes Gracia ${ }^{3}$, and Elson $\operatorname{Longo}^{4 *}$

${ }^{1}$ CDMF-UFSCar, Universidade Federal de São Carlos, P.O. Box 676, 13565-905 São Carlos, SP, Brazil.

${ }^{2}$ IFSC-Universidade de São Paulo, P.O. Box 369, 13560-970 São Carlos, São Paulo, Brazil.

${ }^{3}$ Departament de Química Física i Analítica, Universitat Jaume I, 12071, Castelló de la Plana, Spain.

${ }^{4}$ CDMF-UNESP, Universidade Estadual Paulista, P.O. Box 355, CEP. 14801-907

Araraquara, SP, Brazil

*Juan Andrés, 0034964728081,0034964728086, andres@qfa.uji.es

*Elson Longo, 551633518214, elson.liec@gmail.com 


\section{ABSTRACT}

This article aims to gather together in one place and for first time the formation process of $\mathrm{Ag}$ nanoparticles (NPs) on $\beta-\mathrm{AgVO}_{3}$ crystals, driven by an accelerated electron beam from an electronic microscope under high vacuum. Synthesis and optical properties of $\beta-\mathrm{AgVO}_{3}$ are reported and the relationship between structural disorder and photoluminescence emissions is discussed. First principle calculations, within a QTAIM framework, have been carried out to provide a deeper insight and understanding of the observed nucleation and early evolution of $\mathrm{Ag}$ nanoparticles (NPs) on $\beta-\mathrm{AgVO}_{3}$ crystals. The Ag nucleation and formation is a result of structural and electronic changes of the $\left[\mathrm{AgO}_{5}\right]$ and $\left[\mathrm{AgO}_{6}\right]$ clusters, consistent with $\mathrm{Ag}$ metallic formation. 


\section{INTRODUCTION}

In the past years, materials based on silver vanadium oxide, such as $\mathrm{AgVO}_{3}$, have attracted much interest owing to their technological applications in areas such as sensors, electrical and antibacterial agents, implantable medical devices, and photocatalysts ${ }^{1-14}$. This material is present in two stable phases, namely, $\alpha-\mathrm{AgVO}_{3}$ and $\beta-\mathrm{AgVO}_{3}{ }^{1,15,16}$, both having a monoclinic structure, and $\alpha-\mathrm{AgVO}_{3}$ can be irreversibly transformed to $\beta-\mathrm{AgVO}_{3}$ at around $200{ }^{\circ} \mathrm{C}^{16}$.

$\beta-\mathrm{AgO}_{3}$ exhibits a narrow band gap in the visible region, possessing a high potential as an effective photocatalyst ${ }^{16}$. Recently, experimental and theoretical studies have been reported that focus on the deposition of Ag NPs (with excellent conductivity and strong electron trapping ability) on the surfaces of $\beta-\mathrm{AgVO}_{3}$, which results in enhancing the separation rate of photogenerated holes and electrons ${ }^{2,4}$. Parida et al. synthesized $\beta$ $\mathrm{AgVO}_{3}$ nanobelts decorated with $\mathrm{Ag}$ NPs, and found that decoration alters the saturable absorption and enhances the coefficient of nonlinear absorption of the nanobelts ${ }^{17}$. Mai et al. synthesized the $\beta-\mathrm{AgVO}_{3} /$ polyaniline triaxial nanowires by combining in situ chemical oxidative polymerization and interfacial redox reaction based on $\beta-\mathrm{AgVO}_{3}$ nanowires. They observed that the presence of the Ag NPs enhanced electrochemical performance of the electrodes enabling applications in Li ion batteries ${ }^{18}$.

Our group are engaged in a research project devoted to the study of an unwanted realtime in situ nucleation and growth processes of Ag NPs on different silver based semiconductors such as $\alpha-\mathrm{Ag}_{2} \mathrm{WO}_{4}{ }^{19}, \beta-\mathrm{Ag}_{2} \mathrm{WO}_{4}{ }^{20}, \beta-\mathrm{Ag}_{2} \mathrm{MoO}_{4}{ }^{21,}{ }^{22}$, and $\mathrm{Ag}_{3} \mathrm{PO}_{4}{ }^{23}$, which were driven by accelerated electron beam irradiation from an electron microscope under high vacuum. The reasons for this phenomena have been discussed in recent publications ${ }^{19,22,24,25}$, and the production of $\mathrm{Ag} \mathrm{NPs}$ on $\alpha-\mathrm{Ag}_{2} \mathrm{WO}_{4}{ }^{19,}{ }^{26-29}, \beta$ $\mathrm{Ag}_{2} \mathrm{MoO}_{4}{ }^{30}$, and $\mathrm{Ag}_{3} \mathrm{PO}_{4}{ }^{23}$ resulted in interesting applications as sensors, 
photoluminescent materials, visible-light photocatalysts, and bactericide materials. In this work, we will report, discuss and analyze, for first time, the nucleation process and early evolution of $\mathrm{Ag}$ nanoparticles on $\beta-\mathrm{AgVO}_{3}$ crystals, provoked by an electron beam, by means of the joint use of an experimental and theoretical studies.

In this work, a combined theoretical and experimental study on $\beta-\mathrm{AgVO}_{3}$ has been carried out. The powders have been synthesized by a precipitation method (PM) at 30, 60, and $90{ }^{\circ} \mathrm{C}$ and were characterized using X-ray diffraction (XRD), Raman spectroscopy, field emission scanning electron microscopy (FE-SEM), transmission electron microscopy (TEM) and energy dispersive X-ray spectroscopy (EDS) measurements. Ultraviolet-visible (UV-vis) absorption and photoluminescence (PL) spectroscopy measurements at room temperature were carried out to verify the correlation between the optical properties and the structural order-disorder effects. Calculations, based on density functional theory (DFT), were performed to understand the physical phenomena involved in the nucleation process and early stages of metallic $\mathrm{Ag}$ NPs formation on the surface of $\beta-\mathrm{AgVO}_{3}$, driven by an accelerated electron beam from an electronic microscope under high vacuum

The paper is organized as follows: section 2 describes the experimental procedure (synthesis and characterization) and the theoretical method whereas section 3 consists of results and discussion on the structure and optical properties of $\beta-\mathrm{AgVO}_{3}$, as well as we discuss our results to understand the formation $\mathrm{Ag} \mathrm{NPs}$ on $\beta-\mathrm{AgVO}_{3}$ crystals. Finally, we summarize our main conclusions in section 4. 


\section{EXPERIMENTAL PROCEDURES}

2.1 SYNTHESIS. $\beta-\mathrm{AgVO}_{3}$ powders were obtained by the PM at different temperatures. The precursors used were silver nitrate, $\mathrm{AgNO}_{3}(99 \%$ purity, Synth) and ammonium monovanadate, $\mathrm{NH}_{4} \mathrm{VO}_{3}$ (99\% purity, Merck). Initially, $1 \times 10^{-3}$ mol of $\mathrm{NH}_{4} \mathrm{VO}_{3}$ and $1 \times 10^{-3}$ mol of $\mathrm{AgNO}_{3}$ were separately dissolved in $35 \mathrm{~mL}$ distilled water at $30{ }^{\circ} \mathrm{C}$, under magnetic stirring for $15 \mathrm{~min}$. To determine the effect of temperature on the material properties, the synthesis by means of the PM was performed at 30,60 , and 90 ${ }^{\circ} \mathrm{C}$. Both solutions were quickly mixed, resulting in the instantaneous formation of solid $\beta-\mathrm{AgVO}_{3}$ precipitates (orange color). The precipitate was centrifuged, washed with distilled water several times, and dried in a conventional furnace at $60{ }^{\circ} \mathrm{C}$ for six hours.

2.2 CHARACTERIZATION. $\beta-\mathrm{AgVO}_{3}$ powders were characterized by XRD using $\mathrm{Cu}_{\mathrm{K} \alpha}$ radiation $(\lambda=1.5406 \AA$ ) (Rigaku diffractometer, Model D/Max-2500PC, Japan) in the $2 \theta$ range of 10 to $80^{\circ}$ at a scan speed of rate of $2^{\circ} / \mathrm{min}$ and from 10 to $110^{\circ}$ with at a scan speed of $1 \%$ min in the Rietveld routine, both with a step of $0.02^{\circ}$. Rietveld refinements were performed using the Total Pattern Analysis Solution (TOPAS). Raman spectroscopy measurements were carried out using a T64000 spectrometer (Horiba Jobin-Yvon, Japan) coupled to a CCD Synapse detector and an argon-ion laser, operating at $514 \mathrm{~nm}$ with a maximum power of $7 \mathrm{~mW}$. The spectra were measured in the $100 \mathrm{~cm}^{-1}-1100 \mathrm{~cm}^{-1}$ range. UV-vis spectra were obtained using a Varian spectrophotometer (model Cary 5G, USA) in diffuse reflection mode. The morphologies of the samples were examined using FE-SEM (Supra 35-VP Carl Zeiss, Germany) operated at $15 \mathrm{kV}$. In addition, TEM, at $200 \mathrm{kV}$ and EDS measurements were performed using a FEI microscope (model Tecnai G2 F20, USA). PL measurements were performed with a Monospec 27 monochromator (Thermal Jarrel Ash, USA) 
coupled with a R955 photomultiplier (Hamamatsu Photonics, Japan). A krypton ion laser (Coherent Innova $200 \mathrm{~K}$, USA; $\lambda=350 \mathrm{~nm}$ ) was used as the excitation source with an incident power of approximately $14 \mathrm{~mW}$ on the sample. All measurements were performed at room temperature.

2.3 THEORETICAL METHODS. First-principles total-energy calculations were carried out within the periodic DFT framework using the VASP program ${ }^{32}$. In the calculations, electrons were introduced one by one up to a maximum of four in the monoclinic unit cells of $\beta-\mathrm{AgVO}_{3}$ and the distribution of these extra electrons was calculated by means of a geometry optimization on both the lattice parameters and the atomic positions simultaneously. The Kohn-Sham equations were solved using the Perdew, Burke, and Ernzerhof exchange-correlation functional, and the electron-ion interactions were described by the projector-augmented-wave pseudopotentials ${ }^{33,34}$. The plane-wave expansion was truncated at a cut-off energy of $520 \mathrm{eV}$, and the Brillouin zones were sampled through Monkhorst-Pack special $k$-points grids that assure geometrical and energetic convergence for the $\mathrm{AgVO}_{3}$ structures considered in this work. Vibrational-frequency calculations were performed at the $\Gamma$ point within the harmonic approximation, and the dynamical matrix was computed by numerical evaluation of the first-derivative of the analytical atomic gradients. The keyword NELECT was used in order to increase the number of electrons in the bulk structure, and all the crystal structures were optimized simultaneously with both the volume of the unit-cell and the atomic positions. The relationship between charge density topology and elements of molecular structure and bonding was noted by Bader ${ }^{35}$. This relationship, Bader's quantum theory of atoms in molecules (QTAIM) ${ }^{35-37}$, is now a 
well-recognized tool for analyzing electron density, describing interatomic interactions, and rationalizing chemical bonding.

\section{RESULTS AND DISCUSSION}

Figure 1a shows XRD patterns of $\beta-\mathrm{AgVO}_{3}$ powders synthesized by $\mathrm{PM}$ at 30,60 , and $90{ }^{\circ} \mathrm{C}$. The three samples exhibit similar peaks in the XRD patterns, which can be readily indexed to the monoclinic phase of $\beta-\mathrm{AgVO}_{3}$, with a space group $\mathrm{Cm}\left(\mathrm{n}^{\circ}\right.$. 8). All the diffraction peaks are in good agreement with the Inorganic Crystal Structure Database (ICSD) pattern No. 82079 and indicate the high phase purity in the samples. The definition and intensity of the peaks indicate that $\beta-\mathrm{AgVO}_{3}$ samples have a low degree of long-range periodicity. The Rietveld refinements of $\beta-\mathrm{AgVO}_{3}$ powders are shown in Figure 1b, and their structural results are presented in Table 1, in which the statistic fitting parameters $\left(R_{\mathrm{wp}}\right.$ and GOF) indicate the quality of structural refinement data is acceptable. Significant changes in the lattice parameters and unit cell density were not found in these samples with the syntheses temperature, which are in good agreement with those published in the literature ${ }^{31}$.

$<$ Figure 1a.b $>$

$<$ Table 1>

We performed geometric optimization of the crystal structure by using means of DFT calculations. Graphical representation of the $\beta-\mathrm{AgVO}_{3}$ structure using polyhedra is presented in Figure 2a. $\beta$ - $\mathrm{AgVO}_{3}$ belongs to $\mathrm{Cm}$ space group and the computed unit-cell parameters are $\mathrm{a}=18.677 \AA, \mathrm{b}=3.692 \AA, \mathrm{c}=8.148 \AA$, and $\beta=105.04^{\circ}$. Geometrical parameters of the optimized structure are in agreement with the previously reported 
results ${ }^{38}$. An analysis of the results render that three local coordinations for Ag ions are sensed, corresponding to $\left[\mathrm{AgO}_{\mathrm{x}}\right](\mathrm{x}=5,6$, and 7) clusters while four oxygen atoms are coordinated to a vanadium atom forming the tetragonal $\left[\mathrm{VO}_{4}\right]$ cluster. Distortions in these clusters might induce different kinds of deformations in the $\mathrm{Ag}-\mathrm{O}$ and/or $\mathrm{V}-\mathrm{O}$ bonds as well as $\mathrm{O}-\mathrm{Ag}-\mathrm{O}$ and/or $\mathrm{O}-\mathrm{V}-\mathrm{O}$ bond angles. Subsequently, the positions of $\mathrm{O}, \mathrm{V}$, and $\mathrm{Ag}$ atoms can be varied. A similar phenomenon was previously observed in the case of $\alpha-\mathrm{Ag}_{2} \mathrm{WO}_{4}{ }^{39}$ and $\beta-\mathrm{Ag}_{2} \mathrm{WO}_{4}{ }^{40}$ structures.

Figure $2 \mathrm{~b}$ depicts the polyhedral representation of the unit cell of $\beta-\mathrm{AgVO}_{3} \cdot\left[\mathrm{AgO}_{\mathrm{x}}\right]$ $(\mathrm{x}=5,6$, and 7$)$ and $\left[\mathrm{VO}_{4}\right]$ clusters can be clearly seen as building blocks in this structure. The cluster geometries determined by the DFT calculations are shown in Figure $2 b$.

$<$ Figure 2>

Raman spectroscopy is an effective tool for understanding the effects of structural order and disorder in solids at short ranges. For a perfect crystal, the Raman spectrum should consist of narrow lines corresponding to Raman-allowed zone center point $(\Gamma$ modes) and obey the polarization selection rules. According to group-theory analysis, the allowed representation for each one of the corresponding Wyckoff positions of $\beta$ $\mathrm{AgVO}_{3}$ structure in the $\mathrm{Cm}$ space group indicates 57 Raman-active modes matching the following decomposition at the $\Gamma$ point $\left(\Gamma=38 A^{\prime}+19 A^{\prime \prime}\right)$. The spontaneous Raman spectra and the assigned Raman-active vibration modes of $\beta-\mathrm{AgVO}_{3}$ are presented in Figure 3 and more details are provided in Table S1 in the supplementary information. We could identify fifteen Raman-active modes experimentally. 
The peak at $947 \mathrm{~cm}^{-1}$ could be attributed to the symmetric stretching of the $\mathrm{VO}_{4}$ units $9,41,42$. Vibration bands in this position suggest the presence of polymeric vanadate groups. The most intense peak, located at $884 \mathrm{~cm}^{-1}$, originates either due to bridging in both V-O-Ag and Ag-O-Ag moieties or due to stretching vibrations of O-V-O ${ }^{14,41-45}$. The band at $850 \mathrm{~cm}^{-1}$ can be associated with the stretching vibrations of VO groups in $\left(\mathrm{V}_{2} \mathrm{O}_{7}\right)^{4-}$ ion or with the Ag-O-V vibration. Ag ions are located next to the $\mathrm{VO}_{5}$ groups forming a lamellar double chain, thereby creating favorable conditions for the $\mathrm{Ag}-\mathrm{O}-\mathrm{V}$ bonding ${ }^{41,44,45}$. The band at $804 \mathrm{~cm}^{-1}$ can be assigned to stretching vibrations of the AgO-Ag bridges ${ }^{14,42,45}$. In addition, the bridging $\mathrm{V}-\mathrm{O}-\mathrm{Ag}$ bond and the bridging $\mathrm{V}-\mathrm{O}-\mathrm{V}$ asymmetric stretching bonds in the polymeric metavanadate chains and bending modes of $\mathrm{VO}_{4}$ give rise to bands located at 701 and $731 \mathrm{~cm}^{-114,42-45}$. The bands observed at 678 $\mathrm{cm}^{-1}$ can be attributed to the $\mathrm{V}-\mathrm{O}-\mathrm{V}$ asymmetric vibration ${ }^{41}$. The bridging of $\mathrm{V}-\mathrm{O}-\mathrm{Ag}$ asymmetric stretching bonds in the metavanadate chains and $\mathrm{V}-\mathrm{O}-\mathrm{V}$ stretches bond is reflected by the bands located at $514 \mathrm{~cm}^{-141,44}$.

The Raman bands at 383 and $334 \mathrm{~cm}^{-1}$ can be assigned to the asymmetric deformation modes of the $\mathrm{VO}_{4}{ }^{3-}$ tetrahedron. ${ }^{9,} 10,14,46$ These peaks along with those located at 272, 246, 226, 161 and $121 \mathrm{~cm}^{-1}$ clearly indicate the $\beta-\mathrm{AgVO}_{3}$ structure, similar to that of the channel-structured silver vanadate reported in literature ${ }^{9,44,46}$.

$<$ Figure 3>

For comparison purposes in Table S1 the experimental and calculated values of the Raman-active modes are listed together those reported in the literature. An analysis of the results presented in Table $\mathrm{S} 1$ indicate that both the theoretical and experimental results are in good agreement, while slight variations are sensed in the positions and 
intensities of the peaks of the reported in the literature as compared to those obtained in our study. These changes could arise from many factors, such as differences in the average crystal size, interaction forces between the ions, and the degree of structural order in the lattice.

Figure 4 shows the linear dependence of the modified Kubelka-Munk function $F(R)$ on the photon energy (hv) for the three samples obtained at 30,60 , and $90{ }^{\circ} \mathrm{C}$. The Kubelka-Munk equation (1) for any wavelength is described as:

$$
F\left(R_{\infty}\right) \equiv \frac{\left(1-R_{\infty}\right)^{2}}{2 R_{\infty}}=\frac{k}{S}
$$

where $F\left(R_{\infty}\right)$ is the Kubelka-Munk function or absolute reflectance of the sample, $R_{\infty}=$ $R_{\text {sample }} / R_{\mathrm{MgO}}\left(R_{\infty}\right.$ is the reflectance when the sample is infinitely thick), $k$ is the molar absorption coefficient and $s$ is the scattering coefficient ${ }^{47}$. In a parabolic band structure, the optical band gap and absorption coefficient of semiconductor oxides can be calculated by the following equation (2):

$$
\alpha h v=C_{1}\left(h v-E_{g a p}\right)^{n}
$$

where $\alpha$ is the linear absorption coefficient of the material, $h v$ is the photon energy, $C_{1}$ is a proportionality constant, $E_{\text {gap }}$ is the optical band gap and $n$ is a constant associated with the different kinds of electronic transitions $(n=0.5$ for a direct allowed, $n=2$ for an indirect allowed, $n=1.5$ for a direct forbidden and $n=3$ for an indirect forbidden). Based on this theoretical information, the $E_{\text {gap }}$ values of our metastable $\beta-\mathrm{AgVO}_{3}$ microcrystals were calculated using $n=2$ in equation (2). Finally, using the equation (1) and the term $\mathrm{k}=2 \alpha$ and $C_{2}$ as proportionality constant, is obtained the modified Kubelka-Munk equation as indicated in equation (3):

$$
\left[F\left(R_{\infty}\right) h v\right]^{1 / 2}=C_{2}\left(h v-E_{g a p}\right)
$$


Therefore, finding the $\mathrm{F}\left(\mathrm{R}_{\infty}\right)$ value from equation (3) and plotting a graph of $\left[F\left(R_{\infty}\right) h v\right]^{1 / 2}$ against $h v$, the $\mathrm{E}_{\text {gap }}$ band gap energies of the $\beta-\mathrm{AgVO}_{4}$ was determined ${ }^{48}$.

All the samples exhibited absorption bands in the UV and visible light region. The absorption edge wavelength for $\beta-\mathrm{AgVO}_{3}$ indicates that the two samples prepared at 30 and $60{ }^{\circ} \mathrm{C}$ exhibit similar band gaps, which is different from that of the sample obtained at $90{ }^{\circ} \mathrm{C}$.

$<$ Figure 4>

The values of the band gaps of the $\beta-\mathrm{AgVO}_{3}$ samples synthesized at 30,60 , and $90{ }^{\circ} \mathrm{C}$ are $2.04,2.03$, and $1.88 \mathrm{eV}$, respectively, which is comparable to the values reported in the literature ${ }^{49}$. According to Rietveld refinement (see Table 1) the sample obtained at $90{ }^{\circ} \mathrm{C}$ has a degree of crystallinity higher than samples obtained at 30 and $60^{\circ} \mathrm{C}$. It is well stablished that there is a dependence between the $\mathrm{E}_{\mathrm{g}}$ values with the percentage of amorphous phase ${ }^{50}$. An important feature of the amorphous semiconductor is the existence of defects, i.e. dangling bonds, which are responsible for the formation of some defects in the band structure ${ }^{48,51}$. Generally, when a material with defects is submitted to the heat treatment or at higher temperatures syntheses provokes the presence a crystals lattice more organized, due the reduction of structural defects, oxygen vacancies, decreasing the concentration of intermediary electronic states within band gap and therefore a decreasing the $\mathrm{E}_{\mathrm{g}}$ value ${ }^{52,53}$.

Besides that, it is known that quantum confinement in semiconductor NPs increase the bandgap energy ${ }^{54}$. An analysis of the results of Table 1 renders that the crystallite size of $\beta-\mathrm{AgVO}_{3}$ synthesized at 30 and $60{ }^{\circ} \mathrm{C}$ are the similar, i.e. $13.5 \mathrm{~nm}$, while for sample obtained at $90{ }^{\circ} \mathrm{C}$ the crystallite size is $16.9 \mathrm{~nm}$. According to the literature, 
semiconductor with small crystallite sizes has higher bandgap due to the additional energy from the degree of confinement and Coulomb correlations ${ }^{55}$.

An indirect band gap (at $\mathrm{k} 2$ ) of $1.56 \mathrm{eV}$ and a direct band gap of $2.05 \mathrm{eV}$ are obtained on calculating the band structure of $\beta-\mathrm{AgVO}_{3}$. These values are slightly lower than experimental ones, although in good agreement with them taking into account the underestimation of the band gap values using the PBE functional, being these differences between calculations and experiments typical of DFT calculations. The Brillouin zone with the path used, the band structure, and the DOS projected on atoms are displayed in Figure 5. An analysis of the DOS indicates that the upper part of the valence band consists of noninteracting $\mathrm{Ag} 4 \mathrm{~d}$ and $\mathrm{O} 2 \mathrm{p}$ orbitals and a high contribution of $3 \mathrm{~d} \mathrm{~V}$ and $\mathrm{Ag} 5 \mathrm{~s}$ orbitals are observed in the lower part of the conduction band.

\section{$<$ Figure 5>}

In order to get an insight about the optical properties of the prepared samples, PL measurements were carried out. Figure 6 illustrates the PL spectra at room temperature for the three samples of $\beta-\mathrm{AgVO}_{3}$ synthesized by $\mathrm{PM}$ at 30,60 , and $90{ }^{\circ} \mathrm{C}$, using an excitation wavelength of $350 \mathrm{~nm}$.

The PL spectra profiles exhibit a broad band profiles, which results from multiphonon or multilevel processes. These processes occur in a solid system by several pathways, which involve the participation of numerous energy states within the band gap ${ }^{56,57}$. The spectrum covers a broad range of wavelengths, from 375 to $600 \mathrm{~nm}$, centered at approximately $450 \mathrm{~nm}$ in the blue region of the visible spectra, for all samples. The maximum blue PL emission of $\beta-\mathrm{AgVO}_{3}$ is mainly caused by tetrahedral $\left[\mathrm{VO}_{4}\right]$ clusters in the lattice. The absence of a pronounced red PL emission could be attributed to the 
high degree of distortion caused by $\left[\mathrm{AgO}_{\mathrm{x}}\right](\mathrm{x}=5,6$, and 7) clusters in the matrix and/or affected by the growth of metallic Ag NPs. The sample synthesized at $90{ }^{\circ} \mathrm{C}$ shows higher photoluminescence intensity than that of other samples. This could be attributed to the band-gap decrease (as shown in the UV-vis measurements), which induces a raise in the intermediate levels between the valence and conduction bands, resulting in an increase in the PL emission intensities.

For a better understanding of the PL properties and their dependence on the structural order-disorder of the lattice, the PL curves were deconvoluted with the PeakFit program ${ }^{57}$, as shown in Figure 6. This simulates the experimental PL curve with overlapping peaks and the individual contribution of each component is evaluated by their respective areas and intensities. For this, the PL profiles were adjusted by the addition of three peaks (Area Voigt Function), which were fixed a position in the spectrum.

These peaks correspond to blue (maximum below $448 \mathrm{~nm}$ ), green (maximum below $510 \mathrm{~nm}$ ), and yellow (maximum below $620 \mathrm{~nm}$ ) and they correspond to regions where the maxima of the components appear. At high synthesis temperatures, an increase in the contribution of energetic levels associated with electronic transitions can be observed, which is associated to emissions in the blue light region (shallow holes), as evidenced by an increase in the blue component area. This behavior can be attributed to distributions and organizations of intermediary energy levels within the forbidden band gap.

$<$ Figure 6>

Figure 7 shows the corresponding FE-SEM micrographs of $\beta-\mathrm{AgVO}_{3}$ samples obtained at 30,60 , and $90{ }^{\circ} \mathrm{C}$. No noticeable difference in the crystal shape among the 
three samples was observed. Aggregated $\beta-\mathrm{AgVO}_{3}$ particles with approximately 100 $\mathrm{nm}$ in diameter were observed in all samples. Additionally, the micrographs revealed a high concentration of irregular rod shaped Ag NPs of around $10 \mathrm{~nm}$ in diameter.

$<$ Figure 7>

Figure 8 shows FE-SEM images of $\beta-\mathrm{AgVO}_{3}$ powders obtained before $(\mathrm{A}, \mathrm{C}, \mathrm{E})$ and after $(\mathrm{B}, \mathrm{D}, \mathrm{F}) 3 \mathrm{~min}$ exposure to the electron beam (accelerated at $10 \mathrm{kV}$ ) of the FESEM. Onset of $\mathrm{Ag} \mathrm{NPs}$ on the surface of $\beta-\mathrm{AgVO}_{3}$ is observed immediately after starting the analysis.

$<$ Figure 8>

To verify the growth of metallic Ag NPs on $\beta-\mathrm{AgVO}_{3}$, an EDS system coupled with a TEM microscope was used for analyzing the samples, enabling a local elemental analysis on each individual $\beta-\mathrm{AgVO}_{3}$ microparticles. The samples were subjected to electron beam irradiation in the TEM microscope for 5 min and distinct regions in the focused $\beta-\mathrm{AgVO}_{3}$ microparticles were selected for examination. Figure 9 shows the images for samples synthesized at $90{ }^{\circ} \mathrm{C}$. The samples synthesized at 30 and $60{ }^{\circ} \mathrm{C}$ exhibited similar results and are presented in Figure S1 in the supplementary information. Figures 9a and 9b correspond to the sample before and after irradiation, respectively. In figure 9b, four distinct regions (yellow circles) are selected. Region 1 indicates the presence of an Ag NPs, while no growth can be observed in region 2, as evident from the EDS analysis. As expected, EDS results (Figure 9b, regions 1 and 2) confirmed that the electrons beam promoted the random growth of the metallic Ag NPs, 
since regions with high intensity $\mathrm{Ag}$ peaks and no $\mathrm{Ag}$ peaks in the EDS spectra are present. Carbon and copper atoms are observed in all the EDS analyses, which could be arising from the 300 mesh $\mathrm{Cu}$ grids used in the TEM. We also measured the interplanar distance of an $\mathrm{Ag}$ particle grown on the surface of $\beta-\mathrm{AgVO}_{3}$ from regions 3 and 4 . The (l $\left.1 \begin{array}{ll}1 & 1\end{array}\right)$ and (2 $\left.\begin{array}{lll}2 & 0\end{array}\right)$ planes of metallic $A g$ are separated by $2.359 \AA$ and $2.043 \AA$, respectively (Source: \#PDF65-2871), which are in good agreement with the corresponding values of $2.35 \AA$ and $2.04 \AA$, respectively, measured in our sample (Figure 9b). These values do not correspond to the $\beta-\mathrm{AgVO}_{3}$ phase (\#PDF29-1154), thus confirming the growth of Ag NPs in the material.

$<$ Figure 9>

When the surface of $\beta-\mathrm{AgVO}_{3}$ is irradiated with an electron beam, clusters of $\left[\mathrm{AgO}_{\mathrm{x}}\right]$ interact with the incoming electrons, resulting in the reduction of $\mathrm{Ag}$. Moreover, $\mathrm{Ag}$ migrates from the bulk to the surfaces and it is formed at regions where negatively charged vacancies are present in the crystal lattice. This induces a short- and mediumrange disordering within the semiconductor. The regions with metallic Ag exhibit a ptype semiconducting behavior, as shown in Figure 10. Since silver vanadate is an n-type semiconductor, an $\mathrm{n} / \mathrm{p}$ interface is formed in this region. This interface increases the polarization and consequently, electron/hole recombination becomes more difficult.

$<$ Figure 10>

In Table 2, the bond distance values of $\mathrm{Ag}-\mathrm{O}$ in $\left[\mathrm{AgO}_{\mathrm{x}}\right]$ clusters for $\mathrm{x}=5,6$, and 7 in $\beta-\mathrm{AgVO}_{3}$ are presented as a function of number of electrons added, $\mathrm{N}$. 
$<$ Table 2>

There are two types of $\left[\mathrm{AgO}_{5}\right]$ clusters centered by $\mathrm{Ag} 2$ and $\mathrm{Ag} 3$ atoms (see Figure 2b), both exhibiting similar bond distances and Table 2 provides the average of both these distances. For $\mathrm{N}=2$ and $\mathrm{N}=3$, these two types of $\left[\mathrm{AgO}_{5}\right]$ disappeared and both $\mathrm{Ag}$ atoms were surrounded by three and two $\mathrm{O}$ atoms, respectively. This could be attributed to the approaching of $\mathrm{Ag} 2$ and $\mathrm{Ag} 3$ centers of adjacent cells at distances of $2.645 \AA$ and $2.713 \AA$ for $\mathrm{N}=2$ and $\mathrm{N}=3$, respectively. However, for $\mathrm{N}=4,\left[\mathrm{AgO}_{5}\right]$ cluster formed by $\mathrm{Ag} 2$ remains intact, while $\mathrm{Ag} 3$ is only coordinated to two $\mathrm{O}$ atoms at a distance of 2.494 A. Ag1 and $\mathrm{Ag} 4$ forms $\left[\mathrm{AgO}_{6}\right]$ and $\left[\mathrm{AgO}_{7}\right]$ clusters, respectively. $\mathrm{Ag}-\mathrm{O}$ distances corresponding to $\left[\mathrm{AgO}_{6}\right]$ cluster show a pronounced increase on increasing $\mathrm{N}$ from 0 to 2. However, for $\mathrm{N}=3$ and $\mathrm{N}=4, \mathrm{Ag} 1$ is only bonded to two $\mathrm{O}$ atoms simultaneously and the Ag1-Ag3 distance of the adjacent cells is noticeably shortened to $2.741 \AA$ and 2.745 $\AA$, respectively.

Finally, $\mathrm{Ag} 4$ forms a $\left[\mathrm{AgO}_{7}\right]$ cluster only for $\mathrm{N}=0$; when electrons are added, there is a notable increase in the unit cell distortion as well as in the constitutive polyhedra and $\mathrm{Ag} 4$ is coordinated to 3, 4, 5, and $5 \mathrm{O}$ atoms for $\mathrm{N}=1,2,3$ and 4, respectively. For the four types of $\left[\mathrm{VO}_{4}\right]$ clusters, the four $\mathrm{V}-\mathrm{O}$ distances remain almost unaltered. The electronic charge of each atom was evaluated using Bader charge analysis within the QTAIM framework, by dividing molecules or solids into atoms on the basis of electronic charge density

Finding zero flux surfaces between two atoms allows the atomic charge to be calculated, using integrations of the charge density within the atomic basins, $\Omega$, and subtracting the nuclear charge, $\mathrm{Z}$, of the corresponding atom. The charge density of $\mathrm{Ag}$ 
centers of the $\left[\mathrm{AgO}_{\mathrm{x}}\right](\mathrm{x}=5,6$, and 7$)$ and $\left[\mathrm{VO}_{4}\right]$ clusters as a function of the number of electrons added is depicted in Figure 11.

\section{$<$ Figure 11>}

The zones with high and low charge densities are indicated by the concentration of the charge lines around the atoms. Figures $12 \mathrm{a}, 12 \mathrm{~b}$, and $12 \mathrm{c}$ show $2 \mathrm{D}$ charge density maps for neutral $\beta-\mathrm{AgVO}_{3}$ structure and for samples with $(N=2)$ and $(N=4)$, respectively. The charge density of $\mathrm{Ag} 2$ and $\mathrm{Ag} 3$ centers that initially form $\left[\mathrm{AgO}_{5}\right]$ clusters are similar up to $\mathrm{N}=2$, in which they are 3-fold-coordinated. As more electrons are added, Ag3 is more prone to be reduced than $\mathrm{Ag} 2$.

\section{$<$ Figure 12>}

This could be attributed to the Ag-O bonds, since Ag3 is coordinated to two $\mathrm{O}$ atoms while $\mathrm{Ag} 2$ recovers the five coordination at $\mathrm{N}=4$. Simultaneously, for $\mathrm{N}=0$ to $\mathrm{N}=4$, the Ag2-Ag3 distance decreases from 5.725 to $4.853 \AA$. In addition, a comparison of the three pictures in Figure 12 reveals that the electron density distribution is enhanced between $\mathrm{Ag} 2$ and $\mathrm{Ag} 3$ for $\mathrm{N}=4$. $\mathrm{Ag} 1$ center that forms the $\left[\mathrm{AgO}_{6}\right]$ clusters exhibits a pronounced decrease in the charge density above $\mathrm{N}=2$, due to a change in the coordination number from 6 to 2 . The extra electron density added to the material is transferred from one cluster to another through the lattice, particularly between $\operatorname{Ag} 1$ and Ag3 centers, which behave similarly. At $\mathrm{N}=4$, both $\mathrm{Ag} 1$ and $\mathrm{Ag} 3$ centers are practically reduced and they are coordinated only to two $\mathrm{O}$ atoms, as the $\mathrm{Ag} 1-\mathrm{Ag} 3$ distance of the 
adjacent cells is reduced to $2.745 \AA$. The charge densities of $\mathrm{Ag} 4$ that forms the $\left[\mathrm{AgO}_{7}\right]$ cluster and of $\mathrm{V}$ atoms remain almost unaltered as $\mathrm{N}$ is increased.

\section{CONCLUSIONS}

The main conclusions of the present work can be summarized as follows: i) Theoretical and experimental values of the structural parameters, Raman vibrational frequencies, and band gap of $\beta-\mathrm{AgVO}_{3}$ are in good agreement. ii) The presence of intermediary energy levels within the optical band gap can be attributed to a structural disorder of the tetrahedral $\left[\mathrm{VO}_{4}\right]$ and $\left[\mathrm{AgO}_{\mathrm{x}}\right](\mathrm{x}=5,6$, and 7$)$ clusters, which are the building blocks of $\beta-\mathrm{AgVO}_{3}$. iii) Structural disorder enhances the presence of electronhole pairs, and the PL emissions of the as-synthesized and irradiated $\beta-\mathrm{AgVO}_{3}$ microcrystals depend strongly on the structural disorder of tetrahedral $\left[\mathrm{VO}_{4}\right]$ and $\left[\mathrm{AgO}_{\mathrm{x}}\right](\mathrm{x}=5,6$, and 7) clusters. iv) The in situ growth process of $\mathrm{Ag}$ NPs on the surface of $\beta-\mathrm{AgVO}_{3}$ has been observed for the first time. v) First principle calculations, within the QTAIM framework, have been carried out to investigate the observed nucleation and early evolution of the $\mathrm{Ag}$ NPs on $\beta-\mathrm{AgVO}_{3}$ crystals, driven by an accelerated electron beam from an electronic microscope under high vacuum. The Ag nucleation and formation processes are a result of structural and electronic changes of the $\left[\mathrm{AgO}_{5}\right]$ and $\left[\mathrm{AgO}_{6}\right]$ clusters, consistent with metallic $\mathrm{Ag}$ formation.

\section{SUPPORTING INFORMATION DESCRIPTION}

The Table S1, in the supplementary information, presents a comparison between the experimental and calculated values of the Raman-active modes and those reported in the literature. Figure $\mathrm{S} 1$ shows TEM images of $\beta-\mathrm{AgVO}_{3}$ powders obtained before and after 5 min exposure to the electron beam (accelerated at $10 \mathrm{kV}$ ) for the samples synthesized 
at 30 and $60^{\circ} \mathrm{C}$ by PM. To verify the growth of metallic $\mathrm{Ag} \mathrm{NPs}$ on $\beta-\mathrm{AgVO}_{3}$, an EDS system coupled with a TEM microscope was used for analyzing the samples, enabling a local elemental analysis on each individual $\beta-\mathrm{AgVO}_{3}$ microparticles, Distinct regions in the focused $\beta-\mathrm{AgVO}_{3}$ microparticles were selected for examination.

\section{ACKNOWLEDGMENT}

The authors are grateful to PrometeoII/2014/022 and ACOMP/2014/270 (GeneralitatValenciana), Ministerio de Economia y Competitividad (Spain), CTQ201236253-C03-02 and PRX15/00261, Spanish Brazilian program (PHBP14-00020), FAPESP (FAPESP-CDMF: 2013/07296-2), CNPq and CAPES (for financially supporting this research) and special thanks to Dr. Alan Silva de Menezes of Department of Physics of Universidade Federal do Maranhão by the by Rietveld refinement. L.G. acknowledges Banco Santander (Becas Iberoamérica: Jóvenes profesores e investigadores). J.A. acknowledges Ministerio de Economia y Competitividad, "Salvador Madariaga" program, PRX15/00261. We also acknowledge Servei Informática, Universitat Jaume I, for the generous allotment of computer time.

\section{REFERENCES}

1. Zeng, H.; Wang, Q.; Rao, Y., Ultrafine beta- $\mathrm{AgVO}_{3}$ Nanoribbons Derived from alpha- $\mathrm{AgVO}_{3}$ Nanorods by Water Evaporation Method and Its Application for Lithium Ion Batteries. RSC Advances 2015, 5, 3011-3015.

2. Zhao, W.; Guo, Y.; Wang, S.; He, H.; Sun, C.; Yang, S., A Novel Ternary Plasmonic Photocatalyst: Ultrathin $\mathrm{G}_{-} \mathrm{C}_{3} \mathrm{~N}_{4}$ Nanosheet Hybrided by $\mathrm{Ag} / \mathrm{AgVO}_{3}$ Nanoribbons with Enhanced Visible-Light Photocatalytic Performance. Appl. Catal., B 2015, 165, 335-343.

3. Liang, S.; Zhou, J.; Zhang, X.; Tang, Y.; Fang, G.; Chen, T.; Tan, X., Hydrothermal Synthesis of $\mathrm{Ag} /$ beta- $\mathrm{AgVO}_{3}$ Nanobelts with Enhanced Performance as a Cathode Material for Lithium Batteries. Crystengcomm 2013, 15, 9869-9873. 
4. Zhao, W.; Liang, F.; Jin, Z.-M.; Shi, X.-B.; Yin, P.-H.; Wang, X.-R.; Sun, C.; Gao, Z.-Q.; Liao, L.-S., Efficient Plasmonic Photocatalytic Activity on SilverNanoparticle-Decorated $\mathrm{AgVO}_{3}$ Nanoribbons. J. Mater. Chem. A 2014, 2, 1322613231.

5. Sang, Y.; Kuai, L.; Chen, C.; Fang, Z.; Geng, B., Fabrication of a Visible-LightDriven Plasmonic Photocatalyst of $\mathrm{AgVO}_{3} @ \mathrm{AgBr} @ \mathrm{Ag}$ Nanobelt Heterostructures. ACS Appl. Mater. Interfaces 2014, 6, 5061-5068.

6. $\quad$ Liang, S.; Zhou, J.; Pan, A.; Zhang, X.; Tang, Y.; Tan, X.; Chen, T.; Wu, R., Facile Synthesis of $\mathrm{Ag} / \mathrm{AgVO}_{3}$ Hybrid Nanorods with Enhanced Electrochemical Performance as Cathode Material for Lithium Batteries. J. Power Sources 2013, 228, 178-184.

7. Ju, P.; Fan, H.; Zhang, B.; Shang, K.; Liu, T.; Ai, S.; Zhang, D., Enhanced Photocatalytic Activity of beta- $\mathrm{AgVO}_{3}$ Nanowires Loaded with $\mathrm{Ag}$ Nanoparticles under Visible Light Irradiation. Sep. Purif. Technol. 2013, 109, 107-110.

8. Xu, J.; Hu, C.; Xi, Y.; Wan, B.; Zhang, C.; Zhang, Y., Synthesis and Visible Light Photocatalytic Activity of beta- $\mathrm{AgVO}_{3}$ Nanowires. Solid State Sci. 2012, 14, 535 539.

9. Liang, S.; Zhou, J.; Pan, A.; Li, Y.; Chen, T.; Tian, Z.; Ding, H., Facile Synthesis of beta- $\mathrm{AgVO}_{3}$ Nanorods as Cathode for Primary Lithium Batteries. Mater. Lett. 2012, 74, 176-179.

10. Holtz, R. D.; Lima, B. A.; Souza Filho, A. G.; Brocchi, M.; Alves, O. L., Nanostructured Silver Vanadate as a Promising Antibacterial Additive to Water-Based Paints. Nanomed. Nanotechnol. Biol. Med. 2012, 8, 935-940.

11. Han, C.; Pi, Y.; An Q.; Mai, L.; Xie, J.; Xu, X.; Xu, L.; Zhao, Y.; Niu, C.; Khan, A. M.; He, X., Substrate-Assisted Self-Organization of Radial Beta-Agvo3 Nanowire Clusters for High Rate Rechargeable Lithium Batteries. Nano Lett. 2012, 12, 46684673.

12. Cheng, F.; Chen, J., Transition Metal Vanadium Oxides and Vanadate Materials for Lithium Batteries. J. Mater. Chem. 2011, 21, 9841-9848.

13. Mai, L.; Xu, L.; Gao, Q.; Han, C.; Hu, B.; Pi, Y., Single beta-AgVO $\mathrm{An}_{3} \mathrm{Nanowire}^{-}$ $\mathrm{H}_{2} \mathrm{~S}$ Sensor. Nano Lett. 2010, 10, 2604-2608.

14. Bao, S.-J.; Bao, Q.-L.; Li, C.-M.; Chen, T. P.; Sun, C.-Q.; Dong, Z.-L.; Gan, Y.; Zhang, J., Synthesis and Electrical Transport of Novel Channel-Structured beta-AgVO $\mathrm{A}_{3}$ Small. 2007, 3, 1174-1177.

15. Sharma, S.; Panthofer, M.; Jansen, M.; Ramanan, A., Ion Exchange Synthesis of Silver Vanadates from Organically Templated Layered Vanadates. Mater. Chem. Phys. 2005, 91, 257-260. 
16. Kittaka, S.; Matsuno, K.; Akashi, H., Crystal Structure of alpha-AgVO $\mathrm{AV}_{3}$ and Phase Relation of $\mathrm{AgVO}_{3}$. J. Solid State Chem. 1999, 142, 360-367.

17. Parida, M. R.; Vijayan, C.; Rout, C. S.; Sandeep, C. S. S., Philip R.; Enhanced Optical Nonlinearity in beta- $\mathrm{AgVO}_{3}$ Nanobelts on Decoration with Ag Nanoparticles. Appl. Phys. Lett. 2012, 100, 121119.

18. Mai, L.; Xu, X.; Han, C.; Luo, Y.; Xu, L.; Wu, Y. A.; Zhao, Y., Rational Synthesis of Silver Vanadium Oxides/Polyaniline Triaxial Nanowires with Enhanced Electrochemical Property. Nano Lett. 2011, 11, 4992-4996.

19. Longo, E.; Cavalcante, L. S.; Volanti, D. P.; Gouveia, A. F.; Longo, V. M.; Varela, J. A.; Orlandi, M. O.; Andres, J., Direct in Situ Observation of the ElectronDriven Synthesis of Ag Filaments on alpha- $\mathrm{Ag}_{2} \mathrm{WO}_{4}$ Crystals. Sci. Rep. 2013, 3, 16761680 .

20. Roca, R. A.; Lemos, P. S.; Andres, J.; Longo, E., Formation of Ag Nanoparticles on Metastable beta- $\mathrm{Ag}_{2} \mathrm{WO}_{4}$ Microcrystals Induced by Electron Irradiation. Chem. Phys. Lett. 2016, 644, 68-72.

21. De Santana, Y. V. B.; Cardoso Gomes, J. E.; Matos, L.; Cruvinel, G. H.; Perrin, A.; Perrin, C.; Andres, J.; Varela, J. A.; Longo, E., Silver Molybdate and Silver Tungstate Nanocomposites with Enhanced Photoluminescence. Nanomater. Nanotechno. 2014, 4, 1-10.

22. Andres, J.; Ferrer, M. M.; Gracia, L.; Beltran, A.; Longo, V. M.; Cruvinel, G. H.; Tranquilin, R. L.; Longo, E., A Combined Experimental and Theoretical Study on the Formation of $\mathrm{Ag}$ Filaments on beta- $\mathrm{Ag}_{2} \mathrm{MoO}_{4}$ Induced by Electron Irradiation. Part. Part. Syst. Charact. 2015, 32, 646-651.

23. Botelho, G.; Sczancoski, J. C.; Andres, J.; Gracia, L.; Longo, E., Experimental and Theoretical Study on the Structure, Optical Properties, and Growth of Metallic Silver Nanostructures in $\mathrm{Ag}_{3} \mathrm{PO}_{4}$. J. Phys. Chem. C 2015, 119, 6293-6306.

24. Andres, J., et al., Structural and Electronic Analysis of the Atomic Scale Nucleation of $\mathrm{Ag}$ on alpha- $\mathrm{Ag}_{2} \mathrm{WO}_{4}$ Induced by Electron Irradiation. Sci. Rep. 2014, 4, 5391-5397.

25. Pereira, W. D. S.; Andres, J.; Gracia, L.; San-Miguel, M. A.; da Silva, E. Z.; Longo, E.; Longo, V. M., Elucidating the Real-Time Ag Nanoparticle Growth on alpha$\mathrm{Ag}_{2} \mathrm{WO}_{4}$ During Electron Beam Irradiation: Experimental Evidence and Theoretical Insights. Phys. Chem. Chem. Phys. 2015, 17, 5352-5359.

26. Da Silva, L. F.; Catto, A. C.; Avansi, W., Jr.; Cavalcante, L. S.; Andres, J.; Aguir, K.; Mastelaro, V. R.; Longo, E., A Novel Ozone Gas Sensor Based on OneDimensional (1D) alpha- $\mathrm{Ag}_{2} \mathrm{WO}_{4}$ Nanostructures. Nanoscale 2014, 6, 4058-4062. 
27. Longo, V. M., et al., Potentiated Electron Transference in alpha- $\mathrm{Ag}_{2} \mathrm{WO}_{4}$ Microcrystals with Ag Nanofilaments as Microbial Agent. J. Phys. Chem. A 2014, 118, 5769-5778.

28. Longo, E.; Volanti, D. P.; Longo, V. M.; Gracia, L.; Nogueira, I. C.; Almeida, M. A. P.; Pinheiro, A. N.; Ferrer, M. M.; Cavalcante, L. S.; Andres, J., Toward an Understanding of the Growth of $\mathrm{Ag}$ Filaments on alpha- $\mathrm{Ag}_{2} \mathrm{WO}_{4}$ and Their Photoluminescent Properties: A Combined Experimental and Theoretical Study. $J$. Phys. Chem. C 2014, 118, 1229-1239.

29. Lin, Z.; Li, J.; Zheng, Z.; Yan, J.; Liu, P.; Wang, C.; Yang, G., Electronic Reconstruction of alpha- $\mathrm{Ag}_{2} \mathrm{WO}_{4}$ Nanorods for Visible-Light Photocatalysis. ACS Nano 2015, 9, 7256-7265.

30. Fabbro, M. T.; Saliby, C.; Rios, L. R.; La Porta, F. A.; Gracia, L.; Li, M. S.; Andres, J.; Santos, L. P. S.; Longo, E., Identifying and Rationalizing the Morphological, Structural, and Optical Properties of beta- $\mathrm{Ag}_{2} \mathrm{MoO}_{4}$ Microcrystals, and the Formation Process of Ag Nanoparticles on Their Surfaces: Combining Experimental Data and First-Principles Calculations. Sci. Technol. Adv. Mater. 2015, 16, 65002-65011.

31. Rozier, P.; Savariault, J. M.; Galy, J., beta-AgVO 3 Crystal Structure and Relationships with $\mathrm{Ag}_{2} \mathrm{~V}_{4} \mathrm{O}_{11}$ and delta- $\mathrm{Ag}_{\mathrm{x}} \mathrm{V}_{2} \mathrm{O}_{5}$. J. Solid State Chem. 1996, 122, $303-$ 308.

32. Kresse, G.; Hafner, J., Ab-Initio Molecular-Dynamics Simulation of the LiquidMetal Amorphous-Semiconductor Transition in Germanium. Phys. Rev. B 1994, 49, 14251-14269.

33. Perdew, J. P.; Burke, K.; Ernzerhof, M., Generalized Gradient Approximation Made Simple. Phys. Rev. Lett. 1996, 77, 3865-3868.

34. Kresse, G.; Joubert, D., From Ultrasoft Pseudopotentials to the Projector Augmented-Wave Method. Phys. Rev. B 1999, 59, 1758-1775.

35. Bader, R. F. W., Atoms in Molecules: A Quantum Theory; Oxford University Press: Oxford, 1990.

36. Matta, C. F.; Boyd R. J., The Quantum Theory of Atoms in Molecules, WileyVCH Verlag GmbH \& Co. KGaA: Weinheim, 2007.

37. Popelier, P. L. A.; Aicken, F. M.; O'Brien, S. E., Atoms in Molecules. In Specialist Periodical Reports. Chemical Modelling: Applications and Theory, The Royal Society of Chemistry: Cambridge, 2000.

38. Zhang, S.; Li, W.; Li, C.; Chen, J., Synthesis, Characterization, and Electrochemical Properties of $\mathrm{Ag}_{2} \mathrm{~V}_{4} \mathrm{O}_{11}$ and $\mathrm{AgVO}_{3}$ 1-D Nano/Microstructures. $J$. Phys. Chem. B 2006, 110, 24855-24863.

39. Cavalcante, L. S.; Almeida, M. A. P.; Avansi, W., Jr.; Tranquilin, R. L.; Longo, E.; Batista, N. C.; Mastelaro, V. R.; Siu Li, M., Cluster Coordination and 
Photoluminescence Properties of alpha- $\mathrm{Ag}_{2} \mathrm{WO}_{4}$ Microcrystals. Inorg. Chem. 2012, 51, 10675-10687.

40. Lemos, P. S.; Altomare, A.; Gouveia, A. F.; Nogueira, I. C.; Gracia, L.; Llusar, R.; Andres, J.; Longo, E.; Cavalcante, L. S., Synthesis and Characterization of Metastable beta- $\mathrm{Ag}_{2} \mathrm{WO}_{4}$ : An Experimental and Theoretical Approach. Dalton Trans. 2016, 45, 1185-1191.

41. Holtz, R. D.; Souza Filho, A. G.; Brocchi, M.; Martins, D.; Duran, N.; Alves, O. L., Development of Nanostructured Silver Vanadates Decorated with Silver Nanoparticles as a Novel Antibacterial Agent. Nanotechno. 2010, 21, 185102-185109.

42. Tian, H. J.; Wachs, I. E.; Briand, L. E., Comparison of UV and Visible Raman Spectroscopy of Bulk Metal Molybdate and Metal Vanadate Catalysts. J. Phys. Chem. B 2005, 109, 23491-23499.

43. Zhao, W., et al., Facile in-Suit Synthesis of $\mathrm{Ag} / \mathrm{AgVO}_{3}$ One-Dimensional Hybrid Nanoribbons with Enhanced Performance of Plasmonic Visible-Light Photocatalysis. Appl. Catal., B 2015, 163, 288-297.

44. Song, J.-M.; Lin, Y.-Z.; Yao, H.-B.; Fan, F.-J.; Li, X.-G.; Yu, S.-H., Superlong beta-AgVO $\mathrm{Al}_{3}$ Nanoribbons: High-Yield Synthesis by a Pyridine-Assisted Solution Approach, Their Stability, Electrical and Electrochemical Properties. ACS Nano 2009, 3, 653-660.

45. Zhou, Q.; Shao, M.; Que, R.; Cheng, L.; Zhuo, S.; Tong, Y.; Lee, S.-T., Silver Vanadate Nanoribbons: A Label-Free Bioindicator in the Conversion between Human Serum Transferrin and Apotransferrin Via Surface-Enhanced Raman Scattering. Appl. Phys. Lett. 2011, 98, 193110.

46. Wang, C. B.; Deo, G.; Wachs, I. E., Interaction of Polycrystalline Silver with Oxygen, Water, Carbon Dioxide, Ethylene, and Methanol: In Situ Raman and Catalytic Studies. J. Phys. Chem. B 1999, 103, 5645-5656.

47. Kubelka, P.; Munk, F., Ein Beitrag zur Optik der Farbanstriche. Zeit. Für Tech. Physik 1931, 12 ,593-601.

48. Wood, D. L.; Tauc, J., Weak Absorption Tails in Amorphous Semiconductors. Phys. Rev. B 1972, 5, 3144-3151.

49. Konta, R.; Kato, H.; Kobayashi, H.; Kudo, A., Photophysical Properties and Photocatalytic Activities under Visible Light Irradiation of Silver Vanadates. Phys. Chem. Chem. Phys. 2003, 5, 3061-3065.

50. Deng, H. X.; Wei, S. H.; Li, S. S.; Li, J.; Walsh, A., Electronic Origin of the Conductivity Imbalance Between Covalent and Ionic Amorphous Semiconductors. Phys. Rev. B 2013, 87, 125203. 
51. Zallen, R., The Physics of Amorphous Solids, Wiley-VCH Verlag GmbH \& Co. KGaA: Weinheim, 2004.

52. Anicete-Santos, E.; Picon, F. C.; Escote, M. T.; Leite, E. R.; Pizani, P. S.; Varela, J. A.; Longo, E., Room-Temperature Photoluminescence in Structurally Disordered $\mathrm{SrWO}_{4}$. Appl. Phys. Lett. 2006, 88, 211913.

53. Walsh, A.; Da Silva, J. L. F.; Wei, S. H., Interplay between Order and Disorder in the High Performance of Amorphous Transparent Conducting Oxides. Chem. Mater. 2009, 21, 5119-5124.

54. Sahana, M. B.; Sudakar, C.; Setzler, G.; Dixit, A.; Thakur, J. S.; Lawes, G.; Naik, R.; Naik, V. M.; Vaishnava, P. P., Bandgap Engineering by Tuning Particle Size and Crystallinity of $\mathrm{SnO}_{2}-\mathrm{Fe}_{2} \mathrm{O}_{3}$ Nanocrystalline Composite Thin Films. Appl. Phys. Lett. 2008, 93, 231909.

55. Brus, L., Electronic Wave Functions in Semiconductor Clusters: Experiment and Theory. J. Phys. Chem. 1986, 90, 2555-2560.

56. Longo, V. M.; Cavalcante, L. S.; Paris, E. C.; Sczancoski, J. C.; Pizani, P. S.; Li, M. S.; Andres, J.; Longo, E.; Varela, J. A., Hierarchical Assembly of $\mathrm{CaMoO}_{4} \mathrm{Nano}^{-}$ Octahedrons and Their Photoluminescence Properties. J. Phys. Chem. C 2011, 115, 5207-5219.

57. PEAKFIT, SeaSolve Software Inc 4.12. 


\section{FIGURES}

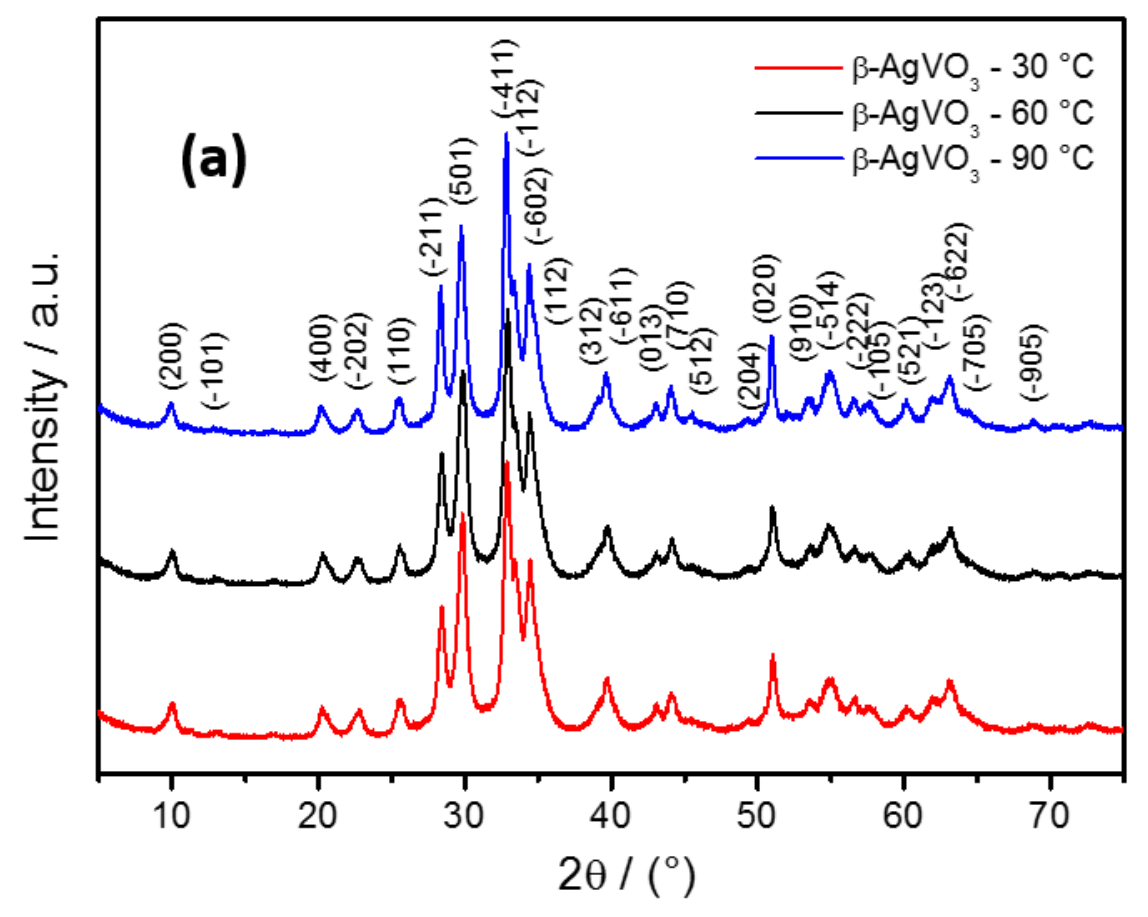

Figure 1. (a) XRD patterns of $\beta-\mathrm{AgVO}_{3}$ powders obtained by the $\mathrm{PM}$ at 30,60 and $90^{\circ} \mathrm{C}$. 

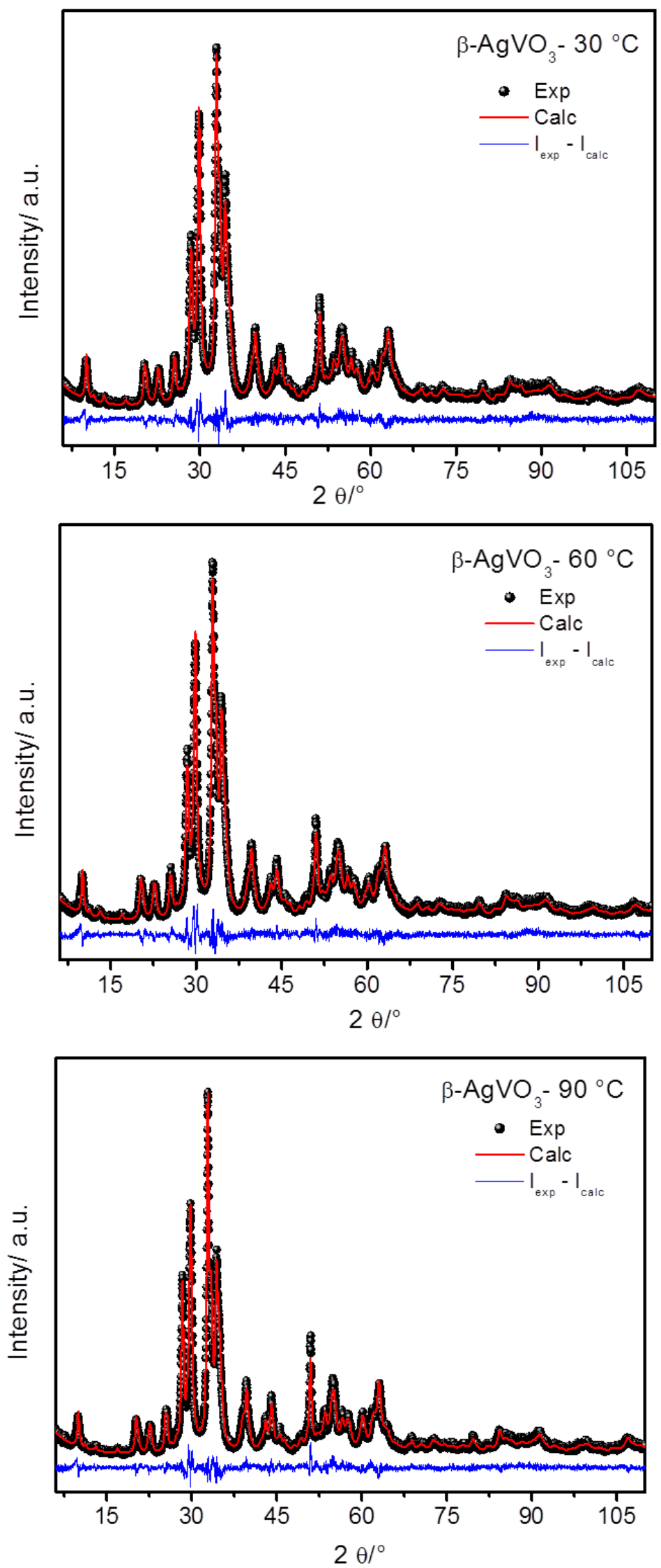

Figure 1. (b) Rietveld refinement plots of $\beta-\mathrm{AgVO}_{3}$ powders obtained by the $\mathrm{PM}$ at 30 , 60 and $90^{\circ} \mathrm{C}$. 


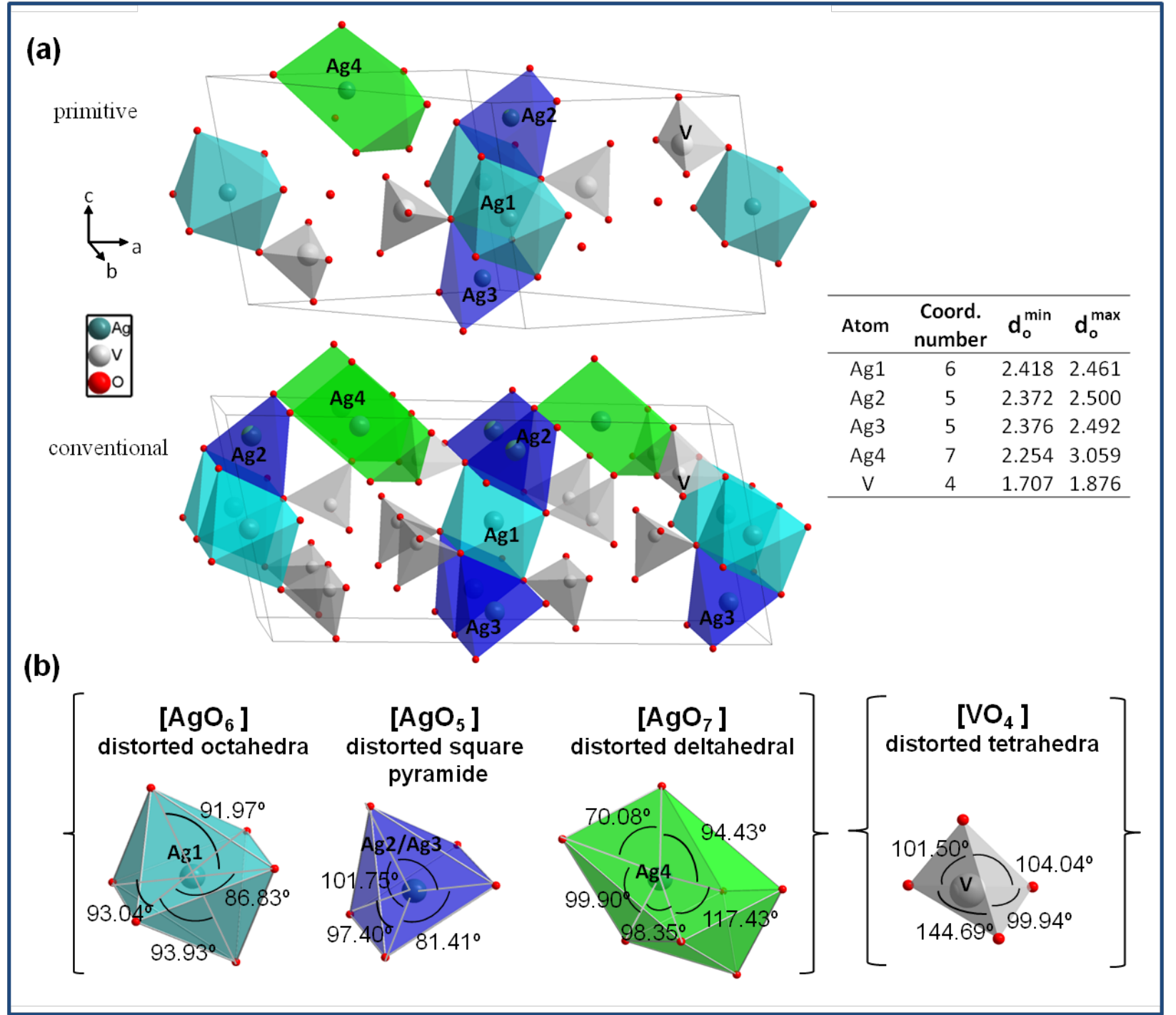

Figure 2. (a) Bulk structure of $\beta-\mathrm{AgVO}_{3}$, in terms of its constituent polyhedra, in the primitive and conventional unit cells; (b) Geometry (angles) of the different clusters determined by DFT calculations. 


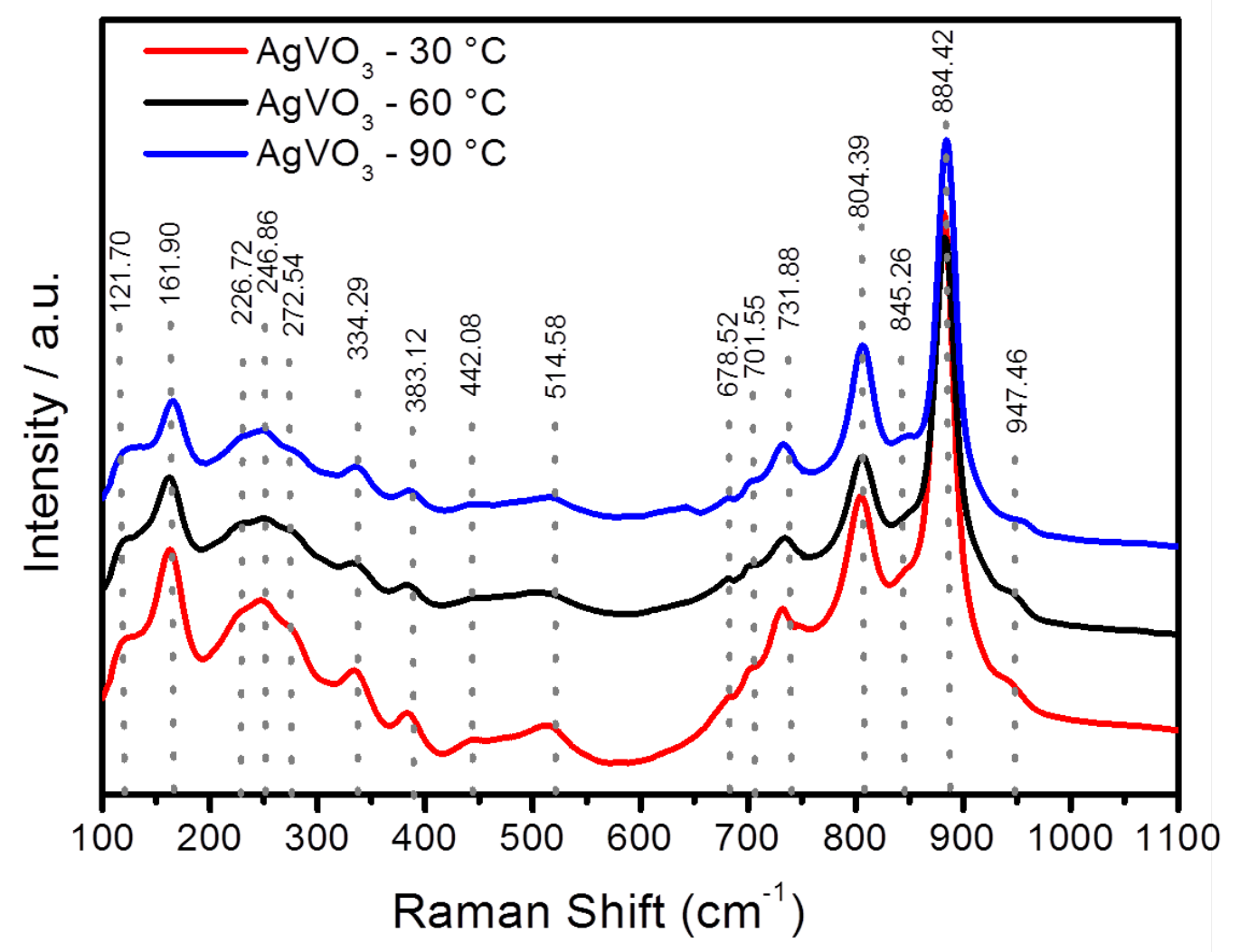

Figure 3. (a) Experimental Ramam spectra of $\beta-\mathrm{AgVO}_{3}$ powders obtained by $\mathrm{PM}$ at 30, 60 and $90^{\circ} \mathrm{C}$. 


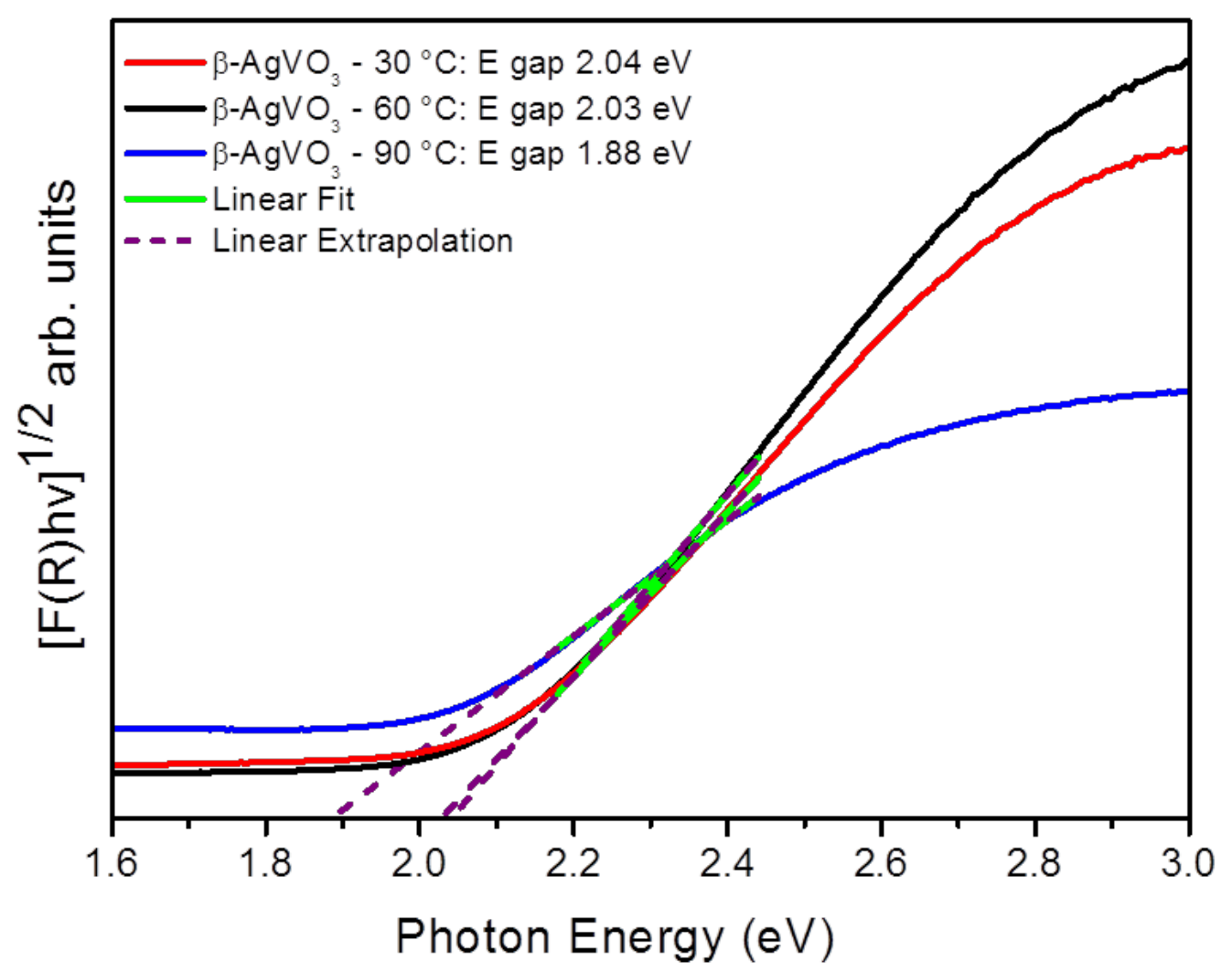

Figure 4. UV-vis diffuse reflectance of $\beta-\mathrm{AgVO} 3$ powders obtained by $\mathrm{PM}$ at 30,60 and $90^{\circ} \mathrm{C}$. 


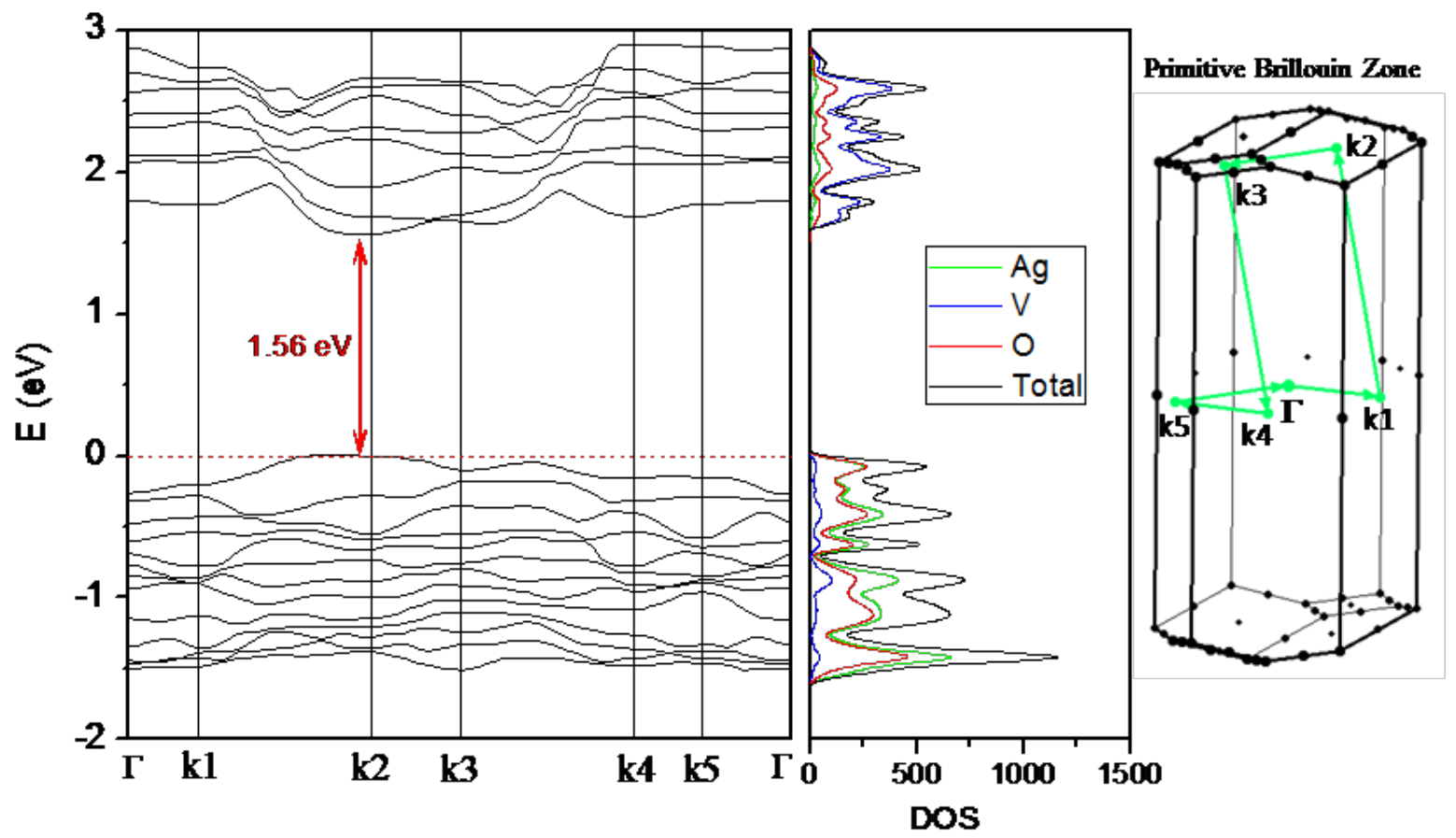

Figure 5. Calculated band structure and density of states projected on atoms for $\beta$ $\mathrm{AgVO}_{3}$. [k1 (110), k2 (100), k3 (011), k4 (001), k5 (111)]. 


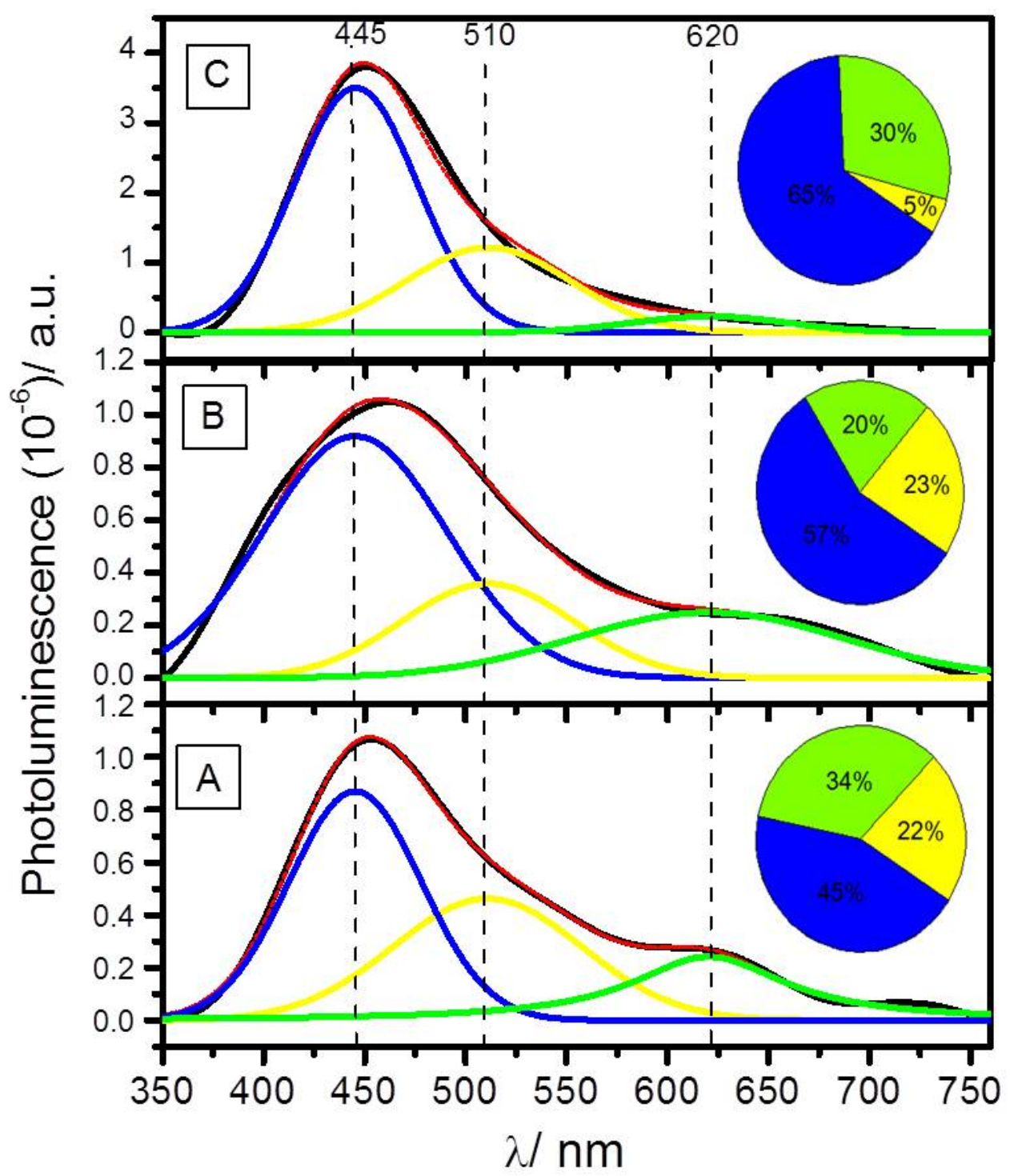

Figure 6. PL Spectra and deconvolution PeakFit of PL Spectra of $\beta-\mathrm{AgVO}_{3}$ powders obtained by $\mathrm{PM}$ at 30 (a), 60 (b) and $90^{\circ} \mathrm{C}(\mathrm{c})$. 


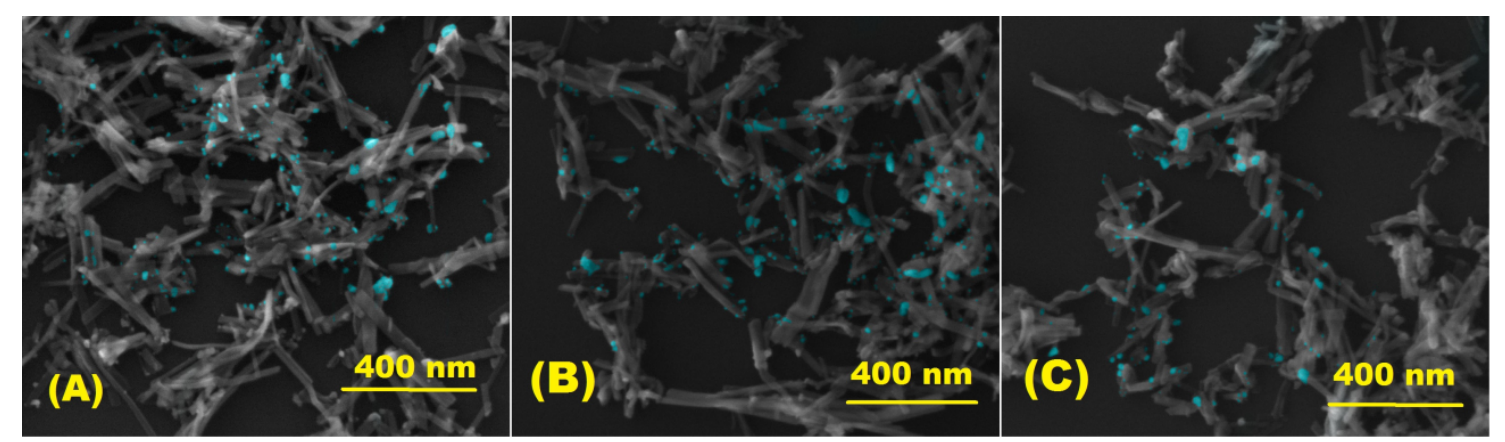

Figure 7. Micrographs of $\beta$ - $\mathrm{AgVO}_{3}$ samples obtained at $30{ }^{\circ} \mathrm{C} \mathrm{(a),60}{ }^{\circ} \mathrm{C}$ (b) and $90{ }^{\circ} \mathrm{C}$ (c). The Ag NPs are painted in blue color. 

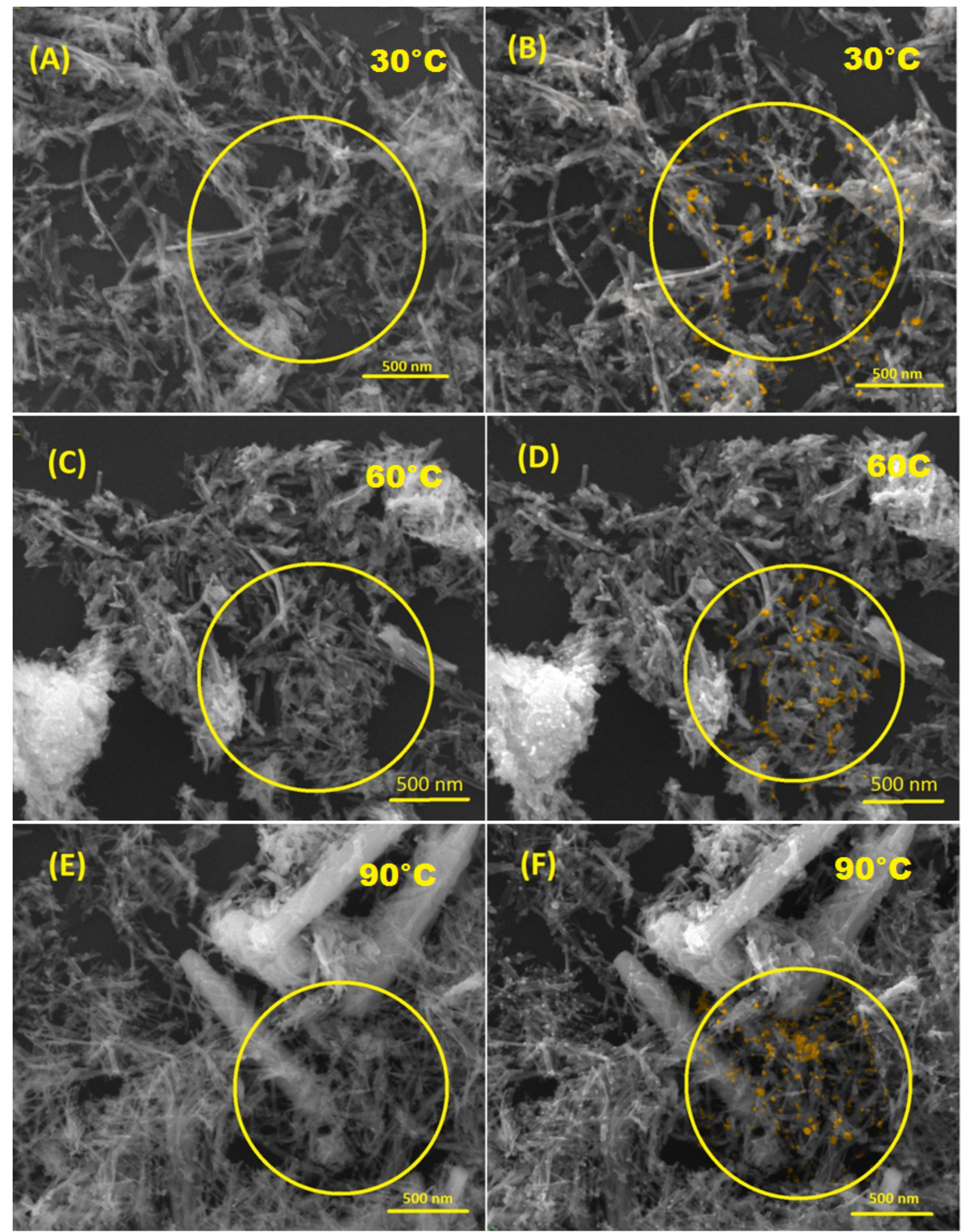

Figure 8. FE-SEM images of $\beta-\mathrm{AgVO}_{3}$ powders before and after a 3 min exposure to the electron beam at different temperatures. The circles on the images indicate the area 
to be focused for the observation of Ag NPS growth with electro irradiation. The Ag NPs are painted in orange color.
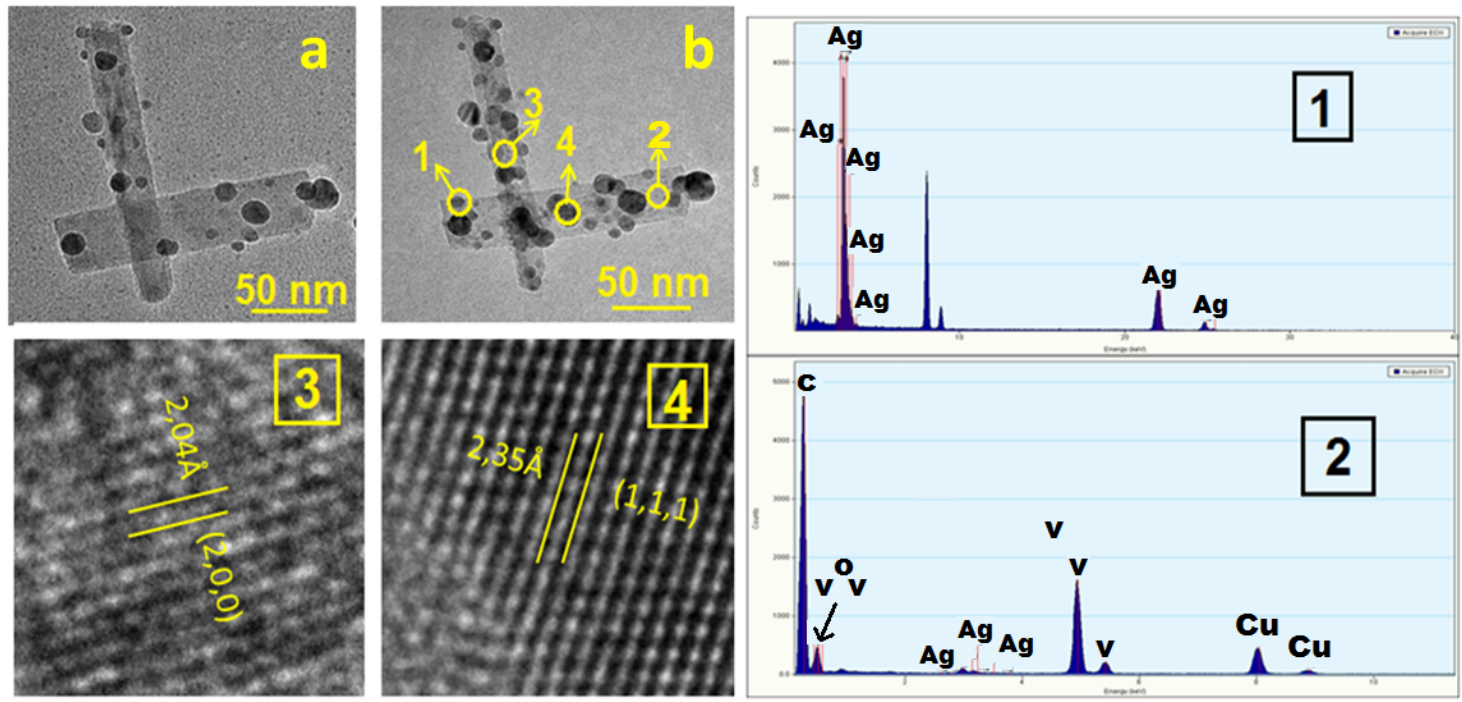

Figure 9. TEM images before and after $5 \mathrm{~min}$ of exposure to the electron beam for $\beta$ $\mathrm{AgVO}_{3}$ powders synthesized by the $\mathrm{PM}$ at $90^{\circ} \mathrm{C}$, illustrating the four regions (yellow circles) used in the chemical compositions (1 and 2), and measurements of the interplanar distances (3 and 4). 


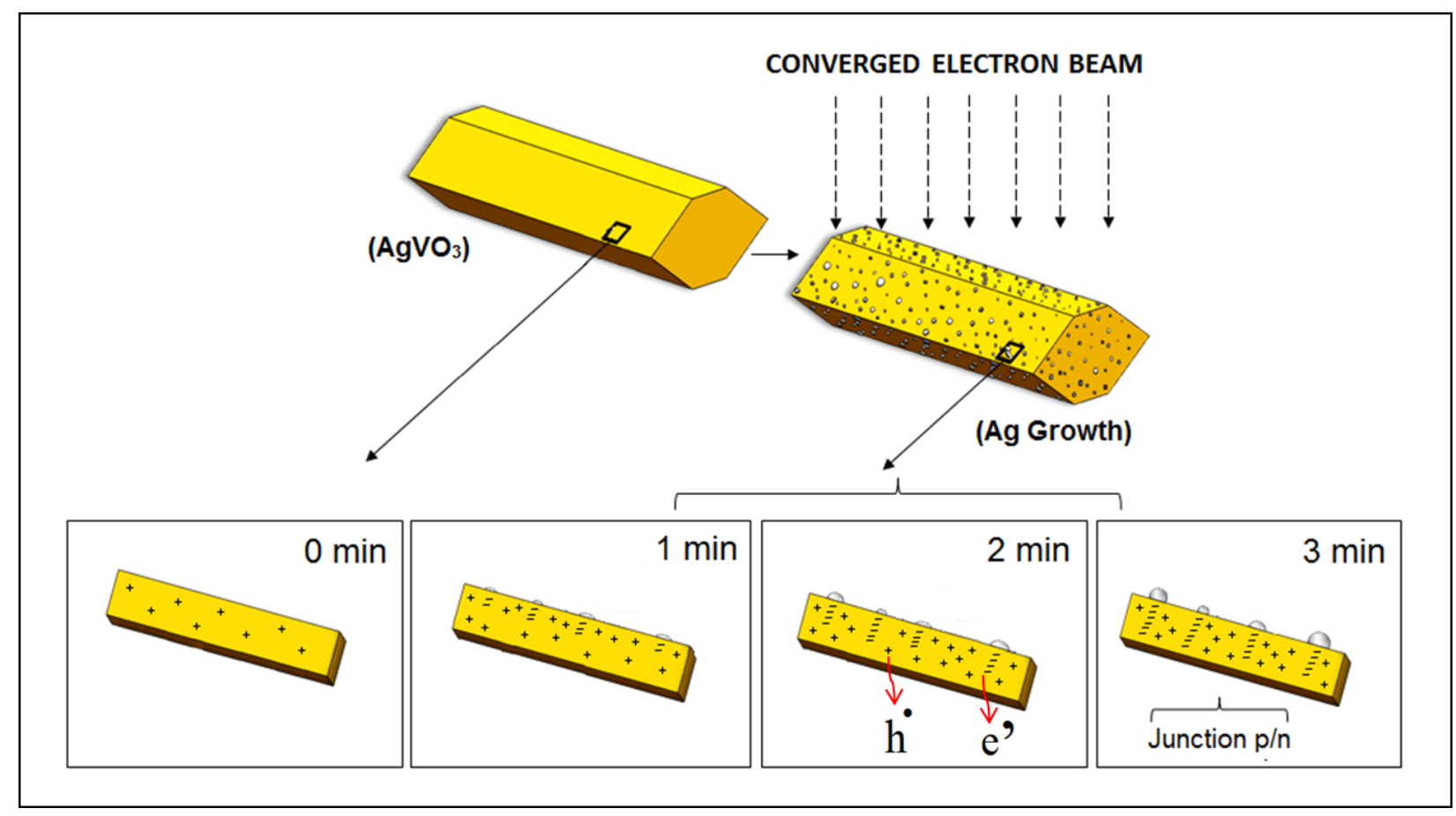

Figure 10. Schematic representation of the silver growth process of and formation of the junction $\mathrm{p} / \mathrm{n}$ after electron irradiation on $\beta-\mathrm{AgVO}_{3}$. 


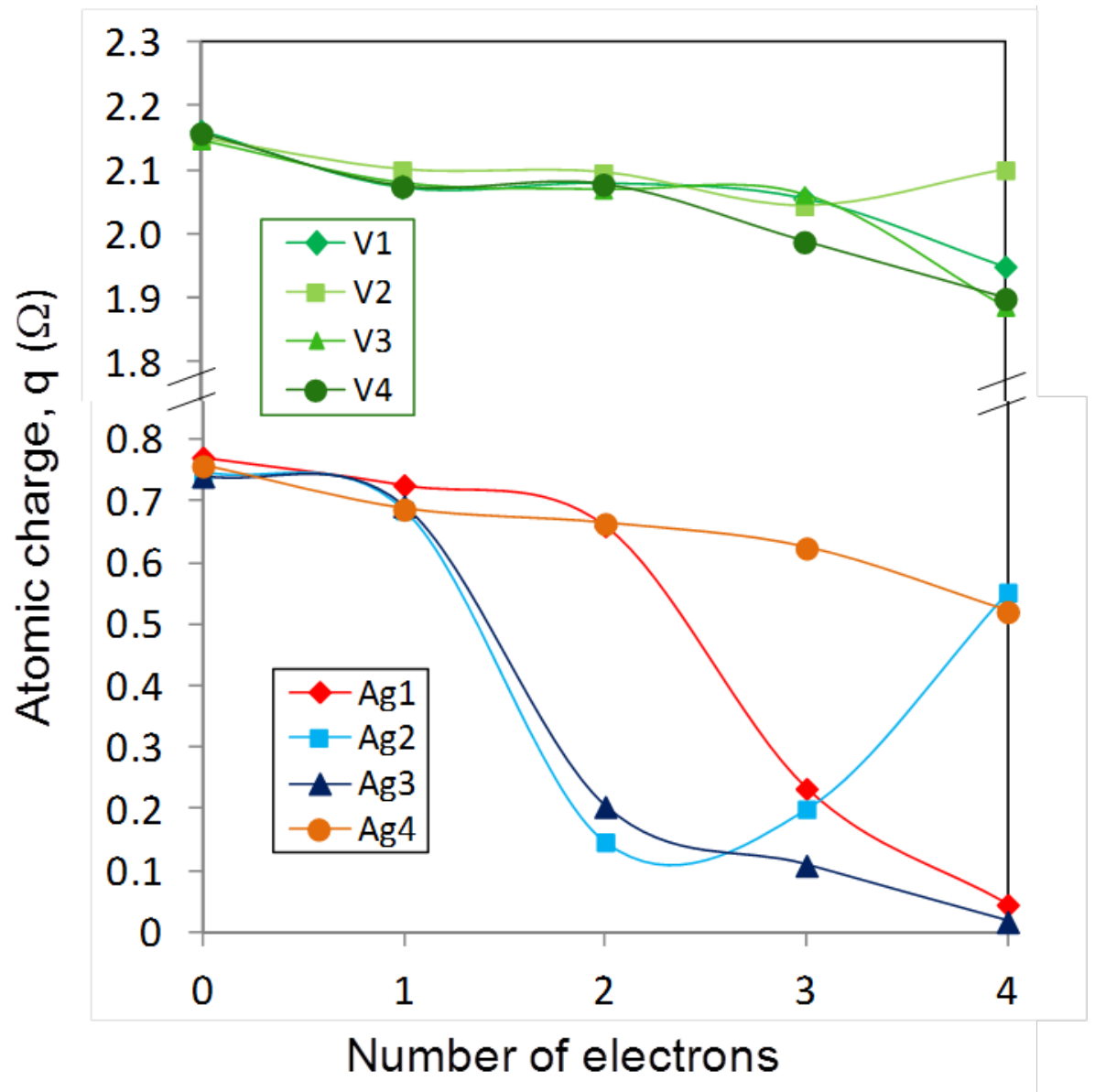

Figure 11. Charge density of the $\mathrm{Ag}$ centers of the $\left[\mathrm{AgO}_{\mathrm{x}}\right](\mathrm{x}=5,6$ and 7$)$ clusters as a function of the number of electrons added for $\beta-\mathrm{AgVO}_{3}$.

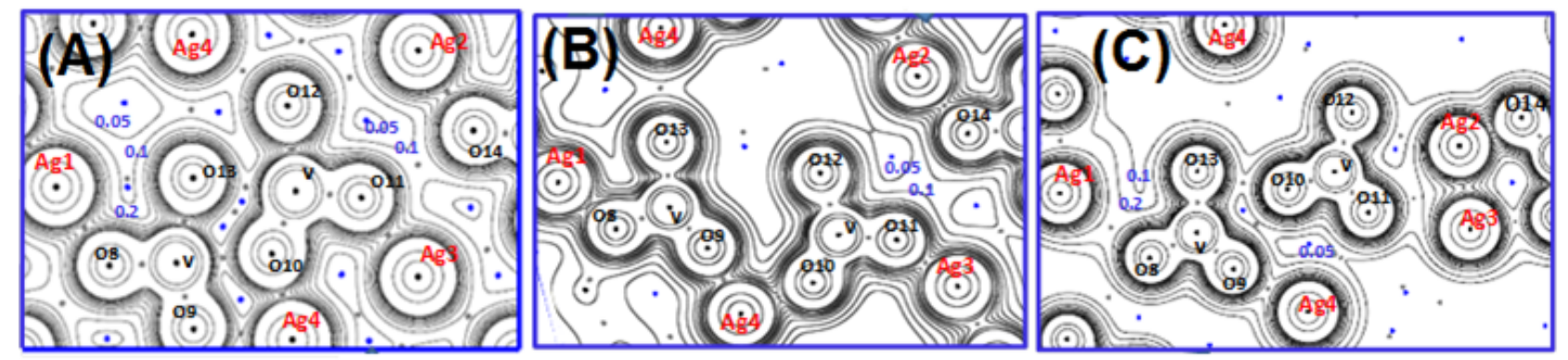

Figure 12. Electron density contours for (a) neutral $(N=0)$ and charged $(b)(N=2)$ and (c) $(\mathrm{N}=4) \beta-\mathrm{AgVO}_{3}$ structure, on a plane containing the four types of $\mathrm{Ag}$ atoms. 
Table 1. Results Obtained from Rietveld Refinements of $\beta-\mathrm{AgVO}_{3}$ powders (DC: Degree of Crystallinity and CS: Crystallite Size).

\begin{tabular}{ccccccccc}
\hline $\begin{array}{l}\text { Temp. } \\
\left({ }^{\circ} \mathbf{C}\right)\end{array}$ & $\mathbf{a}(\AA)$ & $\mathbf{b}(\AA)$ & $\mathbf{c}(\AA)$ & $\boldsymbol{\beta}\left({ }^{\mathbf{o}}\right)$ & $\begin{array}{c}\text { DC } \\
(\mathbf{\%})\end{array}$ & $\begin{array}{c}\mathbf{C S} \\
(\mathbf{n m})\end{array}$ & $\begin{array}{c}\mathbf{R w p} \\
(\boldsymbol{\%})\end{array}$ & $\mathbf{G O F}$ \\
\hline $\mathbf{3 0}$ & 18.123 & 3.578 & 8.043 & 104.469 & 98.4 & 13.5 & 8.3 & 1.3 \\
$\mathbf{6 0}$ & 18.114 & 3.578 & 8.045 & 104.474 & 99.0 & 13.5 & 8.4 & 1.3 \\
$\mathbf{9 0}$ & 18.104 & 3.579 & 8.044 & 104.501 & 99.6 & 16.9 & 8.4 & 1.3 \\
$\mathbf{R e f . 3 1}$ & $\begin{array}{c}18.106 \\
0\end{array}$ & 3.5787 & 8.0430 & 104.440 & - & - & - & - \\
\hline
\end{tabular}

Table 2. Values of Ag-O distance (in $\AA$ ) of the three types of [AgOx] ( $\mathrm{x}=5,6$ and 7) clusters in $\beta-\mathrm{AgVO}_{3}$, as a function of the number of electrons added $(\mathrm{N})$. The multiplicity of the bond is placed in parenthesis.

\begin{tabular}{|c|c|c|c|c|c|c|}
\hline Clusters & $\mathbf{N}$ & $\mathbf{0}$ & 1 & 2 & 3 & 4 \\
\hline \multirow[t]{3}{*}[\mathrm{AgO}_{5}]{} & 2 & 2.375 & 2.385 & 2.345 & 2.340 & 2.343 \\
\hline & 2 & 2.404 & 2.465 & - & - & 2.460 \\
\hline & 1 & 2.500 & 2.517 & 2.775 & - & 2.931 \\
\hline \multirow[t]{3}{*}[\mathrm{AgO}_{6}]{} & 2 & 2.418 & 2.392 & 2.245 & 2.363 & 2.408 \\
\hline & 2 & 2.420 & 2.397 & 2.629 & - & - \\
\hline & 2 & 2.457 & 2.498 & 2.795 & - & - \\
\hline \multirow[t]{4}{*}[\mathrm{AgO}_{7}]{} & 2 & 2.254 & $2.207(1)$ & 2.305 & 2.320 & 2.316 \\
\hline & 2 & 2.360 & - & $2.366(1)$ & 2.460 & 2.590 \\
\hline & 2 & 2.587 & 2.341 & & $2.69(1)$ & $2.72(1)$ \\
\hline & 1 & 2.974 & - & 2.389 & 3.152 & 3.198 \\
\hline
\end{tabular}


